\title{
Disparidades Regionais em Minas Gerais: uma Aplicação Regional de Métodos de Análise Multivariada'
}

\section{Regional Imbalances in Minas Gerais: an Application of Multivariate Analysis}

\author{
Pedro Vasconcelos Amaral* \\ Mauro Borges Lemos** \\ Flávia Chein***
}

\begin{abstract}
Resumo: O objetivo deste trabalho é analisar o processo de desenvolvimento de Minas Gerais no período de 1970 a 2000, com enfoque nas disparidades regionais deste processo e nas características socioeconômicas dos municípios mineiros. Para tanto, foi realizada uma regionalização do Estado visando à identificação de municípios cujo processo de desenvolvimento tenha se dado de forma semelhante. A contribuição específica deste trabalho foi de resgatar a questão do desenvolvimento numa perspectiva multidimensional e a partir daí definir uma regionalização que contemple simultaneamente indicadores econômicos, sociais e demográficos. A regionalização obtida representa um mapeamento tanto da coesão territorial das regióes mineiras bem como de sua fragmentação, o que efetivamente pode servir para a intervenção do planejamento público em áreas-problema da economia estadual.
\end{abstract}

Palavras-chave: Desenvolvimento econômico. Análise regional. Minas Gerais.

Abstract: This article main goal is to analyze the development process of Minas Gerais between the years of 1970 and 2000, focusing on its regional disparities and socioeconomic characteristics. A regionalization of the State was carried through aiming at the identification of cities with similar development process. The specific contribution of this work, using techniques of multivariate analysis, was to review the question of the development in a multidimensional perspective and from defining a regionalization that contemplates simultaneously economic, social and demographic indicators. The obtained regionalization represents a

\footnotetext{
1 Os autores agradecem os comentários recebidos dos pareceristas anônimos

* Mestre em Economia pelo Cedeplar/UFMG. E-mail: pedrovma@cedeplar.ufmg.br

** Doutor e professor titular do Cedeplar/UFMG. E-mail: mbl@cedeplar.ufmg.br

*** Doutora e professora adjunta do Cedeplar/UFMG. E-mail: fchein@cedeplar.ufmg.br.
} 
mapping of the territorial cohesion as well as of its spalling, which can effectively be useful for economic planning in problem-areas of the state economy.

Keywords: Economic development. Regional imbalances. Minas Gerais. JEL Classification: R11.

\section{Introdução}

A literatura de economia regional tem discutido ao longo dos anos a disparidade do desenvolvimento entre as regiões. "We may take it for granted that economic progress does not appear everywhere at the same time and that once it has appeared powerful forces make for a spatial concentration of economic growth" (HIRSCHMAN, 1958, p. 183). A assertiva de Hirschman apresenta-nos um ponto central desta disparidade: a concentração espacial do desenvolvimento. A evolução do capitalismo, desde seus primórdios, tem sido marcada por uma constante e permanente redistribuição espacial das atividades econômicas, com tendência à centralização, que "consiste no desenvolvimento desigual dos centros urbanos" (LEMOS, 1988, p. 217). Se manifestada em limites geográficos, esta tendência resulta na divisão do mundo em países desenvolvidos e subdesenvolvidos, e separam um país em regiões progressistas e atrasadas, centros e periferias (HIRSCHMAN, 1958; FUJITA; KRUGMAN; VENABLES, 1999).

O desenvolvimento desigual entre as regiões brasileiras teve sua dinâmica modificada durante o processo de industrialização após os anos 70, quando os padrões de distribuição espacial da indústria brasileira foram fortemente alterados. Enquanto perdiam importância, as tradicionais regiões produtivas de São Paulo e Rio de Janeiro, outros estados como Minas Gerais, Paraná, Rio Grande do Sul e Santa Catarina começavam a desenvolver suas bases industriais (DINIZ; CROCCO, 1996). Tal desconcentração deu-se não só pela pressão de custos da Região Metropolitana de São Paulo, mas também pela infraestrutura e economias de aglomeração de outras regiões que propiciavam melhores condições locacionais para as novas indústrias. Investimentos em transporte, energia e telecomunicações unificaram o mercado brasileiro e possibilitaram o desenvolvimento também de cidades de médio porte (DINIZ, 1993).

Paradoxalmente, o aumento da demanda industrial impulsionou o crescimento da produção agrícola e mineral e, concomitantemente, os maiores ganhos salariais da indústria atraíram mão de obra do campo para as cidades, redesenhando o perfil urbano do país. 
Minas Gerais, que havia desenvolvido uma economia integrada à de São Paulo, aproveitou-se do processo de desconcentração econômica. O Estado encontra-se no que Diniz (1993) chamou de polígono de desenvolvimento, que teria como vértices Belo Horizonte, Uberlândia, Londrina, Maringá, Porto Alegre, Florianópolis e São José dos Campos. Mas, como demonstra o autor, apenas uma parte do Triângulo, Centro e sul de Minas, encontra-se nesse polígono, o que acentuou as desigualdades regionais dentro do Estado. Cabe, portanto, sob a luz das teorias do desenvolvimento, uma caracterização da desigualdade regional no processo de desenvolvimento em Minas Gerais, intensificada após a década de 70.

Para tanto, foi feita uma regionalização do Estado baseada em atributos municipais sócioeconômicos referentes ao período de 1970 a 2000. Com base nessa regionalização, foi possível caracterizar o processo de desenvolvimento e identificar algumas disparidades regionais neste processo.

Para facilitar seu entendimento, este trabalho foi dividido em três seções, além desta introdução. A primeira é reservada ao referencial teórico que sustenta todo o estudo. A segunda seção trata da metodologia e base de dados utilizadas. Já a terceira, é reservada à discussão dos resultados obtidos e foi divida em três subsseções: a regionalização de Minas Gerais; a ordenação das regiões segundo seu nível de desenvolvimento; e a caracterização socioeconômica intrarregional do processo de desenvolvimento. Seguem-se a esta última seção algumas considerações finais.

\section{O Desenvolvimento Concentrado}

A concentração de uma determinada atividade econômica no espaço ocorre quando existe neste lócus alguma vantagem comparativa em relação aos demais. As vantagens aglomerativas podem reduzir os custos de produção de um bem ou serviço ou aumentar a possibilidade de lucro com sua produção, e são divididas em três grupos distintos: economias internas de escala, economias de localização e economias de urbanização (MARSHALL, 1985; FUJITA; THISSE, 2002; JACOBS, 1969).

Regiões cujo espaço urbano é plenamente diversificado e que detêm vantagens comparativas em relação às demais funcionam como um lócus eminentemente urbano, com capacidade ilimitada de crescimento em função de sua capacidade ilimitada de diversificação, podendo então ser consideradas como um centro (LEMOS, 1988; FUJITA; KRUGMAN; VENABLES, 1999). Mesmo entre regiões centrais, tem-se que a diferente complexidade dos bens e serviços oferecidos nos permite estabelecer 
uma hierarquização econômica das relações interregionais, estabelecendo assim uma rede urbana, de acordo com a Teoria do Lugar Central (CHRISTÄLLER, 1966). O centro, ou lugar central, possui então o papel de provedor de bens e serviços necessários à sobrevivência de seu entorno, ou região complementar. Assim, "[...] a ideia de lugar central aparece a partir desse conceito de centro de uma região onde a densidade de localização da população e das atividades econômicas é maior que na região complementar" (ABLAS, 1978, p. 25). Quanto mais especializados os bens e serviços ofertados pelo lugar central, maior a necessidade de um mercado mínimo para seu consumo e, portanto, mais alto o seu nível de centralidade. Dessa forma, as cidades organizam-se em redes de tamanhos diferentes, com áreas de mercado sobrepostas (LÖSCH, 1967), e sua importância dentro dessa rede é determinada pelas funções por elas desenvolvidas.

Capital e comércio operam fundamentalmente com viés em favor das regiões mais ricas e de maior progresso (MYRDAL, 1957). Assim, as vantagens comparativas dos centros de expansão já estabelecidos, que geralmente funcionam sob retornos crescentes, poderiam até mesmo as atividades que anteriormente existiam em outras regiões. Portanto, as forças do mercado fossem deixadas livres de qualquer interferência política, a produção industrial, o comércio, os bancos, os seguros, a navegação e, de fato, praticamente todas as atividades econômicas para as quais uma economia em desenvolvimento tende a gerar retornos acima da média, seriam agrupadas em certas localidades e regiões, deixando as demais relativamente atrasadas. Tal fato ocorreria também com as ciências, a arte, a literatura, a educação e a cultura em geral. Entretanto, em acréscimo às vantagens locacionais oferecidas pelos centros existentes, outras advêm da proximidade ao centro de crescimento, com sua receptividade especial a inovações e empreendimentos. Ou seja, a proximidade ao centro de progresso também seria capaz de gerar economias externas. Assim, ao analisar o processo de desenvolvimento desbalanceado, seria sempre possível constatar que os avanços em determinado ponto geram tensões, pressões que compelem o crescimento em um ponto subsequente (HIRSHMAN, 1958).

\section{Metodologia e Base de Dados}

Como o desenvolvimento é um conceito multidimensional e dinâmico, sua definição e, principalmente, sua mensuração, são de grande dificuldade. Caracterizar a disparidade no desenvolvimento regional de Minas Gerais requer alguma saída para esse problema. Quais seriam então as características que determinam o nível de desenvolvimento ou 
quão desenvolvida ou subdesenvolvida é uma região em algum ponto do tempo? Uma vez que "[...] nenhum pequeno grupo de variáveis é capaz de capturar a complexa natureza do processo de desenvolvimento" (RAY, 1998, p. 9, tradução nossa), deve-se buscar algum conjunto de variáveis que se correlacionem com o processo multifacetado do desenvolvimento.

Assim, consideradas como uma aproximação e não uma definição de desenvolvimento, foram utilizadas variáveis de diversas dimensões, semelhantes às definidas por Chein, Lemos e Assunção (2005): 1) dimensão populacional; 2) maturidade da população; 3) urbanização; 4) escolaridade; 5) conclusão de graus de ensino; 6) educação infantil; 7) estrutura familiar; 8) condições de moradia; 9) infraestrutura domiciliar; 10) acesso a bens de consumo duráveis; 11) desigualdade; 12) condições gerais do mercado de trabalho; 13) qualidade dos postos de trabalho; 14) massa de rendimentos totais; 15) rendimentos médio / per capita; 16) estrutura ocupacional e 17) estrutura produtiva.

Para o levantamento de dados secundários para a composição das dezessete dimensões, foram utilizados os microdados dos Censos Demográficos de 1970, 1980, 1991 e 2000, realizados pelo IBGE. Desse modo, tem-se abrangência nacional de dados municipais. Cabe ressaltar que a metodologia aplicada nessas pesquisas se alterou ao longo dos anos, sendo necessária a compatibilização de suas variáveis censitárias disponíveis.

Visando a mitigar esse problema, foi usado como referência o Censo Demográfico de 1970, reduzindo-se assim o nível de detalhamento ou desagregação das variáveis dos censos subsequentes. Além disso, as malhas municipais sofreram alterações desde 1970, de modo que se fez necessária também uma compatibilização dessas malhas em unidades territoriais de análise. Para tal, foi utilizada a proposta de compatibilização das malhas municipais para os Censos Demográficos de 1970, 1980, 1991 e 2000 de Chein, Lemos e Assunção (2005). Dessa forma, tornou-se possível agregar os 853 municípios mineiros existentes no ano 2000 em 722 unidades territoriais de análise.

\subsection{Análise de Componentes Principais}

A análise de 58 variáveis em cada um dos quatro últimos anos censitários, num total de 232 variáveis, é extremamente complexa e exaustiva, demandando a utilização de técnicas de análise multivariada, que podem tornar esse grande conjunto de dados mais inteligíveis. Foi então utilizada a Análise de Componentes Principais (ACP) com o objetivo de gerar novos atributos que representem as dezessete dimensões de desenvolvimento apresentadas na seção anterior. Segundo Lemos 
et al. (2001), a vantagem do uso desta técnica está no fato de que ela prescinde de um modelo apriorístico. Assim, não é necessária a definição prévia de um tipo de distribuição, como a normal, ou relações de causalidade.

O método encontra combinações lineares de $p$ variáveis $X_{1}, X_{2}, \ldots, X_{p}$, produzindo componentes $Z_{1}, Z_{2}, \ldots, Z_{p}$ ortogonais não correlacionados (MANLY, 1986). Cada componente explica determinado percentual da variância do sistema, em ordem decrescente, ou seja, o primeiro componente explica um percentual maior que o segundo, que por sua vez explica um percentual maior que o terceiro, e segue-se assim até o componente $Z_{p}$, de modo que o somatório dos percentuais de variância explicados por todos os componentes seja igual 100\%.

Uma vez que são $p$ variáveis, o método pode chegar até a $p$ componentes. No entanto, quando há correlação entre tais variáveis, o número de componentes necessários à explicação da totalidade ou maior parte da variância pode ser menor que $p$. Isto é, quanto maior a correlação entre as variáveis - de forma positiva ou negativa - menor tende a ser a quantidade de componentes.

Para encontrar tanto as variâncias associadas a cada componente, bem como os coeficientes das combinações lineares, o método dos componentes principais utiliza a matriz de covariância ou correlação das variáveis. Neste trabalho, devido às diferentes escalas das variáveis, a matriz de correlação foi escolhida. Os autovalores desta matriz são as variâncias dos componentes calculados, e o valor dos componentes é dado por seus autovetores associados.

Como o somatório dos autovalores corresponde ao traço da matriz de correlação, tem-se:

$$
\lambda_{1}+\lambda_{2}+\ldots+\lambda_{p}=\mathrm{c}_{11}+\mathrm{c}_{22}+\ldots+\mathrm{c}_{p p}
$$

em que $\lambda_{i}$ são os autovalores, ou variância, de cada um dos $i$ componentes.

Uma vez que $c_{i i}$ é a variância de $X_{i}$ e $\lambda_{i}$ a do componente $Z_{i}$, tem-se que a soma das variâncias de todas as variáveis originais é igual à de todos os componentes, o que garante que os componentes respondem por toda a variância do sistema original. Os vetores, as variáveis que os compõem, os componentes resultantes selecionados e o percentual de variância explicada por eles são apresentados no Quadro 2, Apêndice. 


\subsection{Identificação de Regiões Homogêneas: o Método da Árvore Geradora Mínima}

Para facilitar a análise das disparidades no processo de desenvolvimento em Minas Gerais, o Estado foi dividido em quatorze regiões. Os componentes resultantes da ACP, apresentada na seção anterior, foram então utilizados para a delimitação de regiões homogêneas. Foi realizado um agrupamento das unidades territoriais de análise de modo que as unidades pertencentes a um mesmo grupo fossem semelhantes entre si e diferentes das demais. Essa similaridade foi medida de acordo com os atributos de cada unidade territorial, ou seja, de acordo com os valores de seus componentes produzidos pela ACP.

Como o objetivo é a definição de regiões homogêneas, cabe primeiramente uma pequena conceituação do termo região, conforme adotado neste trabalho. Segundo Boudeville (1965), existe uma clara distinção entre espaço econômico e regiões econômicas. O primeiro seria constituído pela intercessão da abstração das relações econômicas com a concretude dos espaços geográficos, independentemente de sua localização ou proximidade. Já uma região econômica seriam espaços com fronteiras comuns, ou seja, espaços contíguos.

Para o autor, a definição de uma região pode ser baseada em três características: i) homogeneidade, referente aos atributos descritivos do espaço-região; ii) interdependência, referente à funcionalidade ou complementaridade desse espaço; iii) região-programa, que seria um espaço econômico contíguo onde se concentram determinadas decisões ou programas, públicos ou privados. Cunha, Simões e Paula (2005) ressaltam ainda que, em uma regionalização cujo objetivo é analisar/ avaliar/estudar/entender qualquer processo natural/político/econômico/ social, região é tudo aquilo que se considera como tal, de acordo com o objetivo que norteia a segmentação do território. Considerando neste trabalho região sob a óptica da homogeneidade do desenvolvimento regional, faz-se necessária para a regionalização do espaço mineiro a utilização de alguma técnica de agrupamento restrito à contiguidade geográfica das unidades territoriais.

Portanto, o método utilizado para a regionalização foi a Árvore Geradora Mínima (ASSUNÇÃO; LAGE; REIS, 2002). Pelo método, o mapa de Minas Gerais é transformado em um grafo em que o centroide de cada unidade territorial de análise é ligado aos centroides de seus vizinhos (unidades com fronteira geográfica comum) por arestas. A cada uma destas arestas é associado um valor $\mathrm{C}$, baseado no vetor de atributos das unidades de análise. 
Aqui, o valor $\mathrm{C}$ de cada aresta é dado por:

$$
\mathrm{C}(\mathrm{i}, \mathrm{k})=\sqrt{\sum_{j=1}^{J}\left(x_{i j}-x_{k j}\right)^{2}}
$$

em que i e k são diferentes áreas de ponderação e j é o vetor de atributos de cada uma.

Em seguida, para obter-se a árvore geradora mínima, são selecionadas as arestas de menor índice $\mathrm{C}$, até que o número de arestas selecionadas seja igual ao número de nós (áreas de ponderação) menos 1 .

Para partição da árvore, ou melhor, definição dos conglomerados, são escolhidas e eliminadas k-1 arestas, para definir-se k regiões. Segundo a proposição dos autores, o benefício de apagar-se uma aresta qualquer é dado pela diferença entre (a) e (b):

(a) É a soma dos quadrados dos desvios no espaço das variáveis em relação à média de todas as áreas da árvore, denominada SSTO:

$$
\mathrm{SSTO}=\sum_{j=1}^{J} \sum_{i=1}^{n}\left(x_{i j}-\bar{x}_{j}\right)^{2} \text { emque, } \quad \bar{x}_{j}=\sum_{i=1}^{J} \frac{x_{i j}}{n}
$$

em que: $J$ é o número total de atributos, $n$ é o número total de áreas de ponderação e $x_{i j}$ é o valor do atributo $j$ na área de ponderação $i$.

(b) E a soma de quadrados dos desvios no espaço em relação à média das variáveis de dois conglomerados resultantes da eliminação de uma aresta, chamada SSA. Quanto menor SSA, mais homogêneos serão os conglomerados resultantes.

Assim, considerando como benefício de se eliminar uma aresta SSTO - SSA, tem-se que um alto benefício associado à aresta indica que seu desaparecimento vai gerar conglomerados homogêneos.

Com base nessas definições, o que se faz é eliminar a aresta que gerará maior benefício, criando duas regiões. Em seguida, repete-se o procedimento dentro de cada conglomerado resultante e apaga-se a aresta de maior benefício entre aquelas dos dois conglomerados. $\mathrm{O}$ algoritmo é finalizado quando forem criadas as k regiões desejadas, o mais homogêneas possível.

\subsection{Hierarquização do Desenvolvimento}

Para a análise interregional do desenvolvimento, sob a premissa de desigualdade regional, a ACP foi mais uma vez aplicada. Entretanto, algumas das dimensões utilizadas para a definição das regiões homogêneas não podem ser diretamente relacionadas ao desenvolvimento no sentido de quanto maiores (ou menores) seus valores, maior seja o 
nível de desenvolvimento de determinada localidade. Atributos como tamanho da população, estrutura etária, condições do mercado e dos postos de trabalho, estrutura familiar, desigualdade e estruturas ocupacionais e produtivas possuem relações bem mais complexas com o nível de desenvolvimento, de modo que, apesar de serem consideradas como características deste, não podem ser levadas em conta em sua hierarquização, ainda que em termos relativos. Assim, o comportamento das regiões mais e menos desenvolvidas em relação a tais atributos foi considerado posteriormente à hierarquização, na Seção 4.2. Visando a obter a posição relativa do desenvolvimento de cada região homogênea em cada ponto do tempo de análise - 1970, 1980, 1991 e 2000 -, a ACP foi utilizada com base nas variáveis municipais que compõem os vetores ${ }^{2}$ de urbanização, educação I e II, infraestrutura domiciliar, acesso a bens de consumo duráveis, rendimento total e rendimentos médios, para cada um dos períodos de análise, de modo a obtermos um componente para cada ano que respondesse por grande parte da variância de todo o sistema.

Como os componentes foram gerados para as unidades territoriais de análise, foi calculada sua média para cada região, ponderada pela população das unidades territoriais respectivas ao período do tempo em questão. Desse modo, foram obtidos quatro componentes, referentes a 1970, 1980, 1991 e 2000, para cada região homogênea. A classificação do nível de desenvolvimento das regiões foi feita pela ordenação desses componentes. Pretendeu-se assim identificar e caracterizar dissimilaridades entre as regiões que podem ser resultantes de desigualdade em seus respectivos processos de desenvolvimento no período de análise.

\subsection{Análise Intrarregional: o Método Partitioning Around Medoids}

Já a análise intrarregional foi realizada principalmente através de uma caracterização econômica das regiões, suas dinâmicas urbanas e setoriais sob o contexto de hierarquias urbanas e aglomerações ou especializações setoriais. Para isso, foi utilizado outro método de agrupamento, o Partitioning Around Medoids (PAM), que não possui a restrição de contiguidade imposta pela Árvore Geradora Mínima. Este método de agregação, como qualquer outro, busca agrupar objetos com alto grau de similaridade, de modo que os semelhantes se encontrem em um mesmo grupo e os dessemelhantes em grupos diferentes.

O algoritmo utilizado pelo método se baseia na definição de $k$ objetos representativos, em que $k$ é a quantidade de grupos que deve ser

2 Ver Quadro 2 do Apêndice. 
definida previamente. Uma vez definidos os $k$ objetos representativos, são criados $k$ grupos, designando os demais objetos para os grupos dos representativos com que possuam maiores similaridades (KAUFMAN; ROUSSEEUW, 1990). Dessa forma, tem-se a minimização da dissimilaridade média interna de cada grupo.

O método PAM possui uma vantagem de grande importância sobre os demais métodos de agrupamento e classificação. Como mostram Kaufman e Rousseeuw (1990), a definição e caracterização de um objeto capaz de representar os vários aspectos estruturais do conjunto a ser investigado torna a análise dos resultados bem mais simples e prática.

As variáveis padronizadas que foram utilizadas para o agrupamento intrarregional das unidades territoriais de análise encontram-se no Quadro 1.

\begin{tabular}{|c|c|}
\hline Variáveis Utilizadas - Agropecuária & Base de Dados \\
\hline Rebanho bovino & PPM 2003 - IBGE \\
\hline Produção agrícola & PAM 2003 - IBGE \\
\hline Emprego setorial (\%) & Censo Demográfico 2000 - IBGE \\
\hline \multicolumn{2}{|l|}{ Indústria } \\
\hline Valor da transformação industrial & PIA 2002 - IBGE \\
\hline Emprego setorial (\%) & Censo Demográfico 2000 - IBGE \\
\hline $\begin{array}{l}\text { Total rendimentos do trabalho principal } \\
\text { no setor industrial }\end{array}$ & Censo Demográfico 2000 - IBGE \\
\hline \multicolumn{2}{|l|}{ Serviços } \\
\hline Arrecadação municipal de ISSQN & FINBRA - MF, 2003 \\
\hline Quantidade de agências bancárias & BACEN, 2004 \\
\hline Emprego setorial (\%) & Censo Demográfico 2000 - IBGE \\
\hline \multicolumn{2}{|l|}{ Demográficas } \\
\hline População & Censo Demográfico 2000 - IBGE \\
\hline Percentual de população urbana & Censo Demográfico 2000 - IBGE \\
\hline $\begin{array}{l}\text { Percentual de domicílios com acesso à rede } \\
\text { geral de escoamento }\end{array}$ & Censo Demográfico 2000 - IBGE \\
\hline Escolaridade média & Censo Demográfico 2000 - IBGE \\
\hline Rendimento médio & Censo Demográfico 2000 - IBGE \\
\hline
\end{tabular}

Quadro 1 - Variáveis Utilizadas para Classificação Intrarregional e suas

Fontes

Fonte: Elaborado pelos autores. 


\section{Regionalização do Desenvolvimento de Minas Gerais (1970-2000)}

A presente seção apresenta os resultados da caracterização do desenvolvimento desigual de Minas Gerais. Sob a premissa das disparidades regionais, a primeira seção apresenta as regiões homogêneas definidas para o Estado, com o objetivo de congregar em uma mesma região as unidades territoriais de análise cujo processo de desenvolvimento tenha sido mais semelhante. Com base na compatibilização geográfica apresentada na Seção 3, entende-se por município, a partir deste ponto do trabalho, as unidades territoriais de análise. Ou seja, entende-se por município a área geográfica resultante da compatibilização das malhas municipais no período entre 1970 e 2000 . Um exemplo claro é a classificação de Iturama como detentor do maior rebanho bovino do Estado. De acordo com a Pesquisa Agropecuária Municipal de 2003, o município que possui maior rebanho bovino é Prata, localizado no Triângulo Mineiro. Entretanto, a unidade territorial de análise chamada Iturama é composta pelos municípios Iturama, Carneirinho, Limeira do Oeste e União de Minas, que em conjunto possuem rebanho bovino superior à Prata. Cabe ressaltar que raras foram as distorções oriundas da compatibilização geográfica como esta em todo o trabalho.

\subsection{As Regiões Homogêneas de Minas Gerais}

A segmentação do território mineiro com o objetivo de que fossem formadas regiões cujo processo de desenvolvimento interno fosse mais semelhante que o de municípios pertencentes a outras regiões, através do método Árvore Geradora Mínima, apresentado na Seção 3.2, resultou em quatorze regiões, apresentadas na Figura 1. 


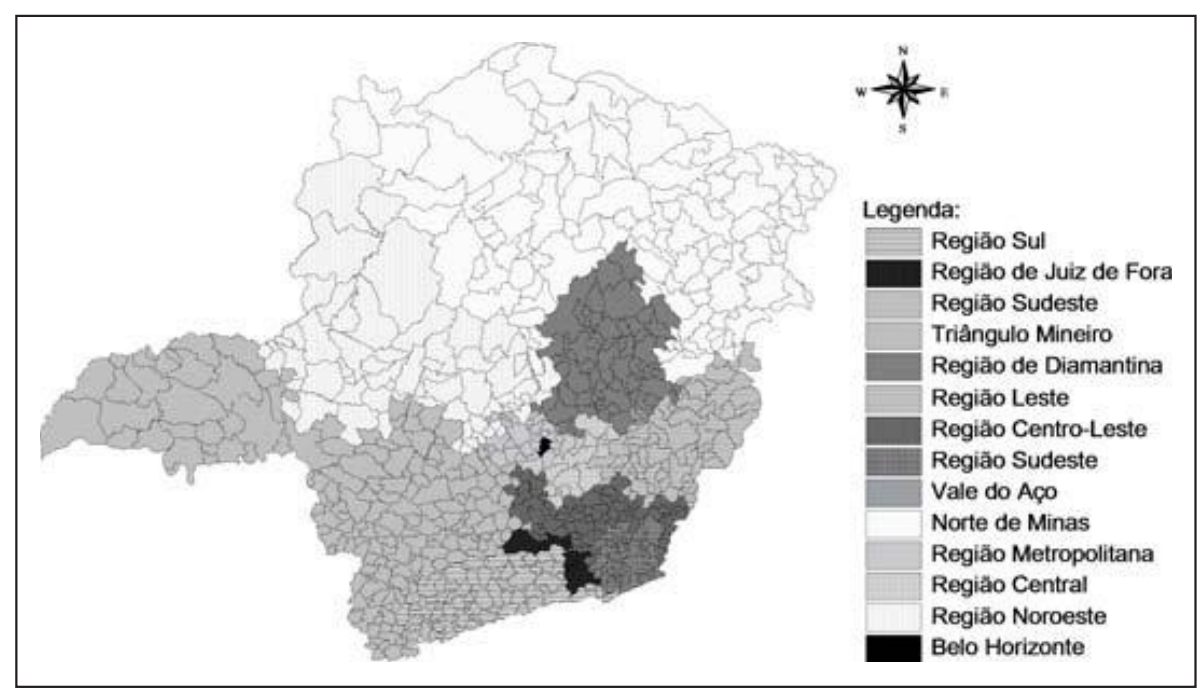

Figura 1 - Regiões Homogêneas - Minas Gerais ${ }^{3}$

Fonte: Elaborada pelos autores com base na malha municipal digital de 2002 (IBGE).

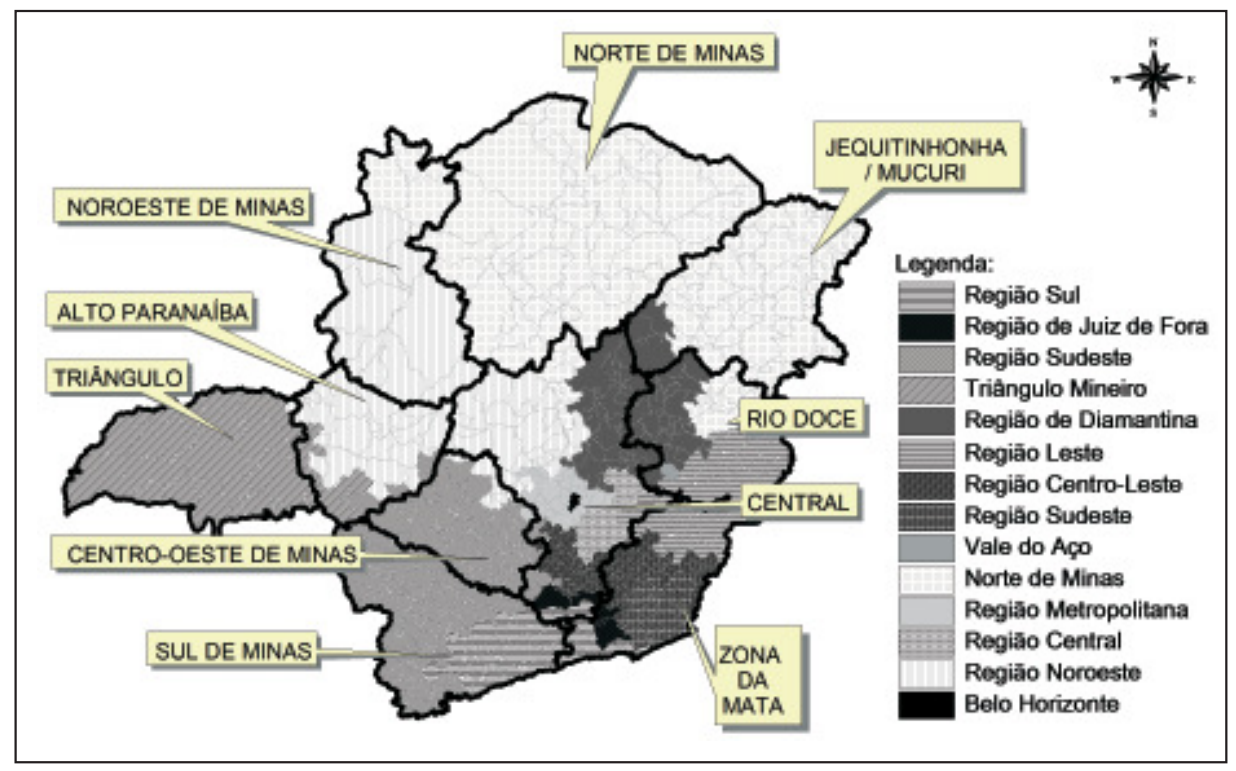

Figura 2 - Comparação entre as Regiões Homogêneas e as Regiões de Planejamento

Fonte: Elaborada pelos autores com base na malha municipal digital de 2002 (IBGE).

As regiões homogêneas são bem diferentes das Regiões de Planejamento, definidas em 1995 pelo Plano Mineiro de Desenvolvimento Integrado. O Estado é segmentado em dez Regiões de Planejamento, sendo a maior delas a região Norte, assim como em nossas regiões homogêneas. Entretanto, como mostra a Figura 2, a divisão de Minas Gerais

3 As figuras deste trabalho estão disponíveis em cores em $<$ http://sites.google.com/site/pedrovma/publicacoes $>$. 
feita neste trabalho inclui na região Norte praticamente todo o Vale do Jequitinhonha/Mucuri e mais alguns municípios, uma vez que o processo de desenvolvimento de ambas no período analisado é bem semelhante.

A diferença mais notável cabe à Região de Planejamento Central. Seus municípios foram distribuídos em nada menos que onze regiões homogêneas, tamanha a desigualdade no processo de desenvolvimento entre seus componentes. Dentre as regiões homogêneas, o município de Belo Horizonte compõe sozinho a sua própria região, como era de se esperar. Em seu entorno, tem-se uma região que se aproxima da Região Metropolitana oficial, composta por municípios não apenas bem distintos da capital, mas também dos demais da Região Central, muitos dos quais, por sua vez, possuem mais semelhança territorial com seus vizinhos de outras Regiões de Planejamento.

As diferenças nas demais regiões, como Rio Doce, Sul de Minas e Zona da Mata, são consequências dos diferentes níveis de desenvolvimento encontrados internamente a essas Regiões de Planejamento, conforme caracterização na Seção 4.3.

Cabe ressaltar que a regionalização apresentada neste trabalho não deve de modo algum ser considerada como uma proposta de regionalização para pesquisas com quaisquer outros objetivos que não de estritamente analisar o desenvolvimento regional mineiro nas dimensões aqui utilizadas. A definição deste escopo restrito para o delineamento das regiões possui a vantagem de chegar a resultados mais precisos para o objetivo deste trabalho, mas gera grandes distorções caso sejam outros os objetivos para os quais a regionalização possa ser utilizada. $\mathrm{O}$ fato de não considerarmos aqui dimensões físicas, políticas, históricas e culturais, entre outros fatores, deve estar sempre em vista.

\subsection{O Desenvolvimento Comparado}

Com o resultado da Análise de Componentes Principais realizada separadamente para cada um dos anos 1970, 1980, 1991 e 2000, é possível realizarmos uma análise comparativa do nível de desenvolvimento das regiões homogêneas neste período do tempo. Pode-se destacar que os resultados são relativos, não indicando se uma região pode ser de fato considerada desenvolvida ou não-desenvolvida, mas apenas se a mesma encontrava-se em um estágio de desenvolvimento superior ou inferior às demais, segundo os fatores selecionados para sua mensuração, em determinado período do tempo. Além disso, os valores dos componentes principais de um ano podem ser comparados somente a outros do mesmo período, não sendo possíveis comparações interperíodos. 
A Tabela 1 apresenta as posições relativas das regiões nos anos selecionados. Como são 14 regiões, a posição 1 indica a região de Minas Gerais que se encontrava mais desenvolvida, enquanto a posição 14 indica a que se encontrava com menor estágio de desenvolvimento. As regiões estão ordenadas de acordo com sua posição relativa em 2000. As colunas prin70, prin80, prin91 e prin00, da Tabela 1, apresentam os valores médios do componente principal para cada região nos anos 1970, 1980, 1991 e 2000.

Como esperado, Belo Horizonte apresentou o maior nível de desenvolvimento do Estado durante todo o período analisado, com larga vantagem indicada pela diferença entre os componentes principais da capital e da segunda colocada, a região de Juiz de Fora. Entretanto, a Região Metropolitana de Belo Horizonte atingiu em 2000 apenas a sétima colocação, o que indica a grande diferença entre os níveis de desenvolvimento da capital e de seu entorno imediato. Esta região é composta por 26 municípios e, apesar dos avanços no total de rendimentos e na taxa de conclusão do Ensino Fundamental (em taxas anualizadas, a elevação foi de $10,2 \%$ e 7,5\% entre 1970 e 2000, respectivamente, enquanto a média estadual foi de 7,3\% e 6,6\%), ainda encontra-se relativamente atrasada no que tange à renda média e remuneração média do trabalhador (em taxas anualizadas, $0,8 \%$ e 2,9\% em contrapartida a $1,7 \%$ e 3,9\% no Estado, entre 1970 e 2000), o que indica que apesar do crescimento da renda total ter sido superior à média do Estado, o crescimento da população também o foi, de modo superior (Gráficos 1 e 2).

Tabela 1 - Valor Médio do Componente Principal e Posição Relativa do Desenvolvimento - Regióes Homogêneas (1970-2000)

\begin{tabular}{c|c|c|c|c|c|c|c|c}
\hline Região & prin70 & prin80 & prin91 & prin00 & $\mathbf{1 9 7 0}$ & $\mathbf{1 9 8 0}$ & $\mathbf{1 9 9 1}$ & $\mathbf{2 0 0 0}$ \\
\hline Belo Horizonte & 5.25 & 4.36 & 4.27 & 4.00 & 1 & 1 & 1 & 1 \\
\hline Juiz de Fora & 3.27 & 2.69 & 2.65 & 2.41 & 2 & 2 & 2 & 2 \\
\hline Triângulo & 1.53 & 1.82 & 2.04 & 1.92 & 5 & 4 & 3 & 3 \\
\hline Vale do Aço & 2.34 & 2.23 & 1.88 & 1.75 & 3 & 3 & 4 & 4 \\
\hline Centro & 1.90 & 1.77 & 1.52 & 1.34 & 4 & 5 & 5 & 5 \\
\hline Sudoeste & 0.84 & 1.04 & 1.13 & 1.16 & 9 & 9 & 7 & 6 \\
\hline Metropolitana & 1.39 & 1.28 & 1.26 & 1.11 & 6 & 6 & 6 & 7 \\
\hline Sul & 1.16 & 1.08 & 1.09 & 1.11 & 7 & 7 & 8 & 8 \\
\hline Sudeste & 1.15 & 1.05 & 1.02 & 0.98 & 8 & 8 & 9 & 9 \\
\hline Noroeste & 0.40 & 0.65 & 0.83 & 0.86 & 10 & 10 & 10 & 10 \\
\hline Centro-Leste & 0.21 & 0.15 & 0.02 & 0.11 & 11 & 11 & 11 & 11 \\
\hline & & & & & & & (continua)
\end{tabular}




\begin{tabular}{c|c|c|c|c|c|c|c|c}
\hline Leste & -0.36 & -0.30 & -0.39 & -0.28 & 12 & 12 & 12 & 12 \\
\hline Norte & -0.75 & -0.63 & -0.62 & -0.65 & 14 & 13 & 13 & 13 \\
\hline Diamantina & -0.73 & -0.88 & -0.84 & -0.87 & 13 & 14 & 14 & 14 \\
\hline
\end{tabular}

Fonte: Elaborada pelos autores.

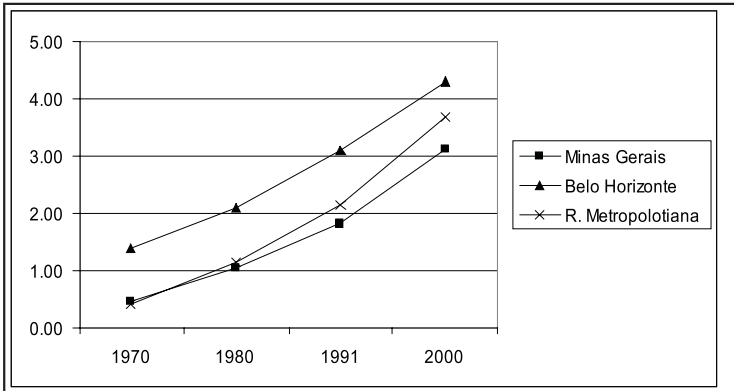

Gráfico 1 - Log da Média dos Rendimentos Totais (1970-2000) Fonte: Elaborado pelos autores.

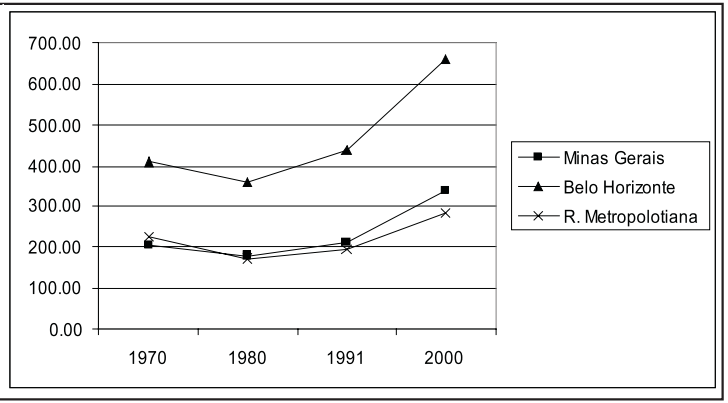

Gráfico 2 - Renda Média (R\$) (1970-2000)

Fonte: Elaborado pelos autores.

As últimas colocações são ocupadas pelas regiões Norte e Diamantina, que, como mostra a Figura 1, compõem toda a porção nordeste de Minas Gerais, excetuando-se os três municípios do Vale do Aço, que constituem numa região própria. Estas regiões revezaram suas posições ao longo dos anos e se encontram em níveis próximos de desenvolvimento. A região Norte é constituída pelo Norte de Minas, Jequitinhonha/ Mucuri e partes do Noroeste, Rio Doce e Região Central. Alavancada principalmente pelos municípios de Governador Valadares e Montes Claros, destaca-se pelos seus ganhos absolutos, como o grande esforço de alfabetização e escolarização. Entre 1970 e 1980, a média de anos de estudo da população de 25 anos ou mais cresceu 79\%, enquanto no Estado esse crescimento foi de 52\%. Já entre 1991 e 2000, esse crescimento foi de $37 \%$, contra $22 \%$ em Minas Gerais, e a taxa de alfabetização na região teve aumento de $10 \%$, enquanto a média estadual foi de apenas $0,5 \%$. Entretanto, a região ainda encontra-se abaixo da média de Minas Gerais nesses dois quesitos. A escolaridade média da população de 25 anos ou mais no Norte é de 3,94 anos, e a taxa de alfabetização é 68\%, enquanto no Estado tem-se 5,51 anos e 79\%, respectivamente. A região manteve-se atrasada em relação às demais, principalmente devido à pouca melhora nos índices de consumo, às crianças trabalhando e à renda média. 


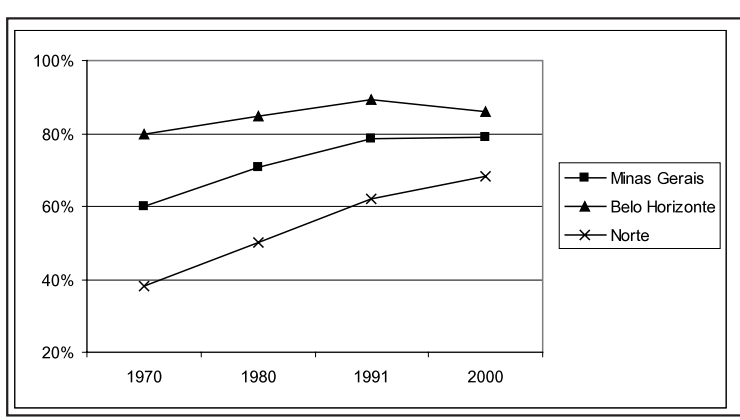

Gráfico 3 - Taxa de Alfabetização (1970-2000)

Fonte: Elaborado pelos autores.

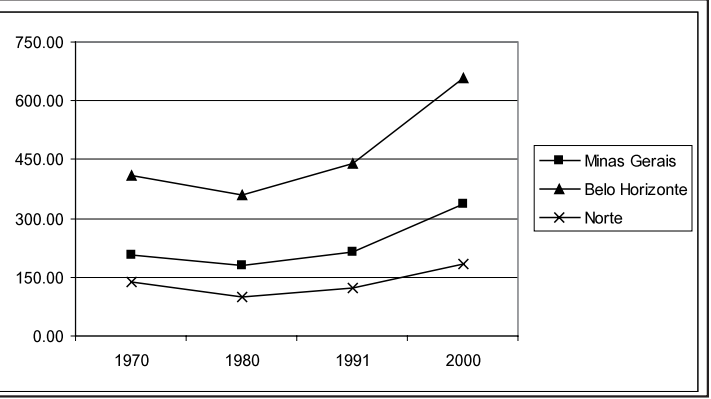

Gráfico 4 - Renda Média (R\$)

(1970-2000)

Fonte: Elaborado pelos autores.

A região de Diamantina é formada pelo nordeste da Região de Planejamento Central, noroeste do Rio Doce e Alto Jequitinhonha. Passou por uma grande melhoria de infraestrutura entre 1991 e 2000, elevando suas taxas de atendimento de escoamento por rede geral, iluminação elétrica e abastecimento por rede geral em 116\%, 48\% e 39\%, respectivamente, enquanto em Minas Gerais foram 27\%, 12\% e 13\%, entretanto as melhoras nos níveis de renda, analfabetismo e crianças fora da escola e/ou trabalhando ficaram muito aquém da média estadual.

Cabe ainda ressaltar a proximidade dessa região de Belo Horizonte. O município Taquaraçu de Minas, pertencente à região de Diamantina, encontra-se a apenas 63 quilômetros da capital. Tal proximidade entre as regióes de maior e menor desenvolvimento revela as fortes disparidades regionais em Minas Gerais, inclusive em áreas contíguas ao aglomerado metropolitano. Um dos principais problemas são os desníveis de infraestrutura na economia estadual, acentuados pelo precário sistema de transportes, que limita os efeitos de espraiamento ou gotejamento do desenvolvimento entre as regiões, fortalecendo ainda mais sua tendência centralizadora, intensificando as disparidades regionais.

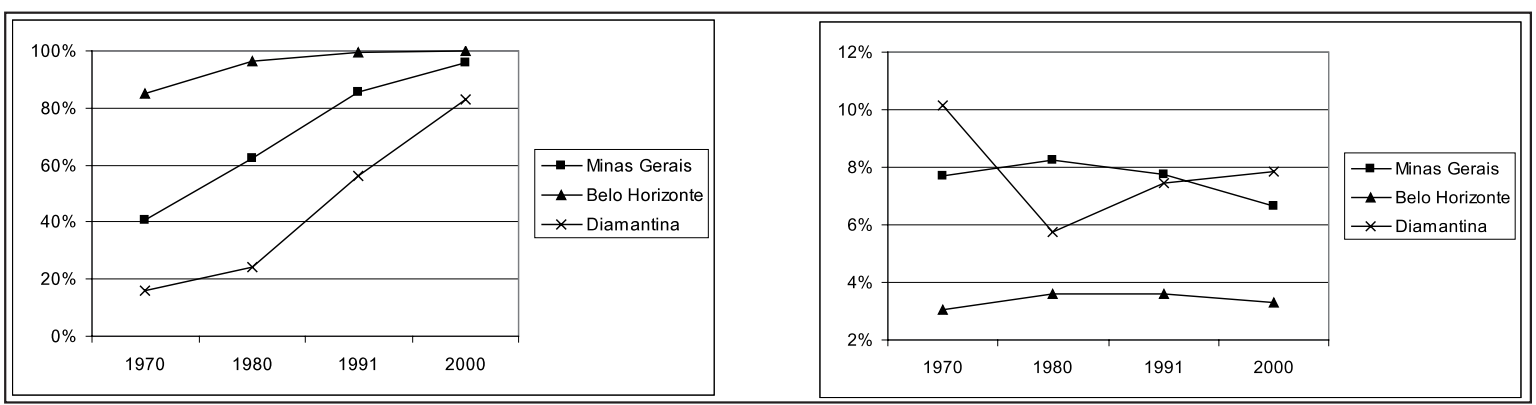

Gráfico 5 - \% da População com Iluminação Elétrica (1970-2000) Fonte: Elaborado pelos autores.

Gráfico 6 - \% de crianças que trabalham (1970-2000)

Fonte: Elaborado pelos autores. 


\subsection{Análise Intrarregional}

A análise intrarregional baseou-se nos resultados obtidos pela análise de componentes principais, apresentada na Seção 3.1. Buscou-se descrever nessa seção como sendo atributos regionais característicos aqueles cujos componentes possuíam menor desvio padrão internamente à região, além daqueles cuja média mais se distanciou de zero, que é a média dos componentes para todas as regiões. A definição de grupos, ou clusters, realizada pelo método Partioning Around Medoids, apresentado na Seção 3.4, não possui hierarquização definida pelo modelo. A classificação do cluster como 1, 2, 3 ou $n$ foi meramente observacional, visando a aproximar-se da hierarquia urbana local, com base nas Regiões de Influência das Cidades (INSTITUTO BRASILEIRO DE GEOGRAFIA E ESTATÍSTICA, 2000).

\subsubsection{Belo Horizonte e seu entorno metropolitano}

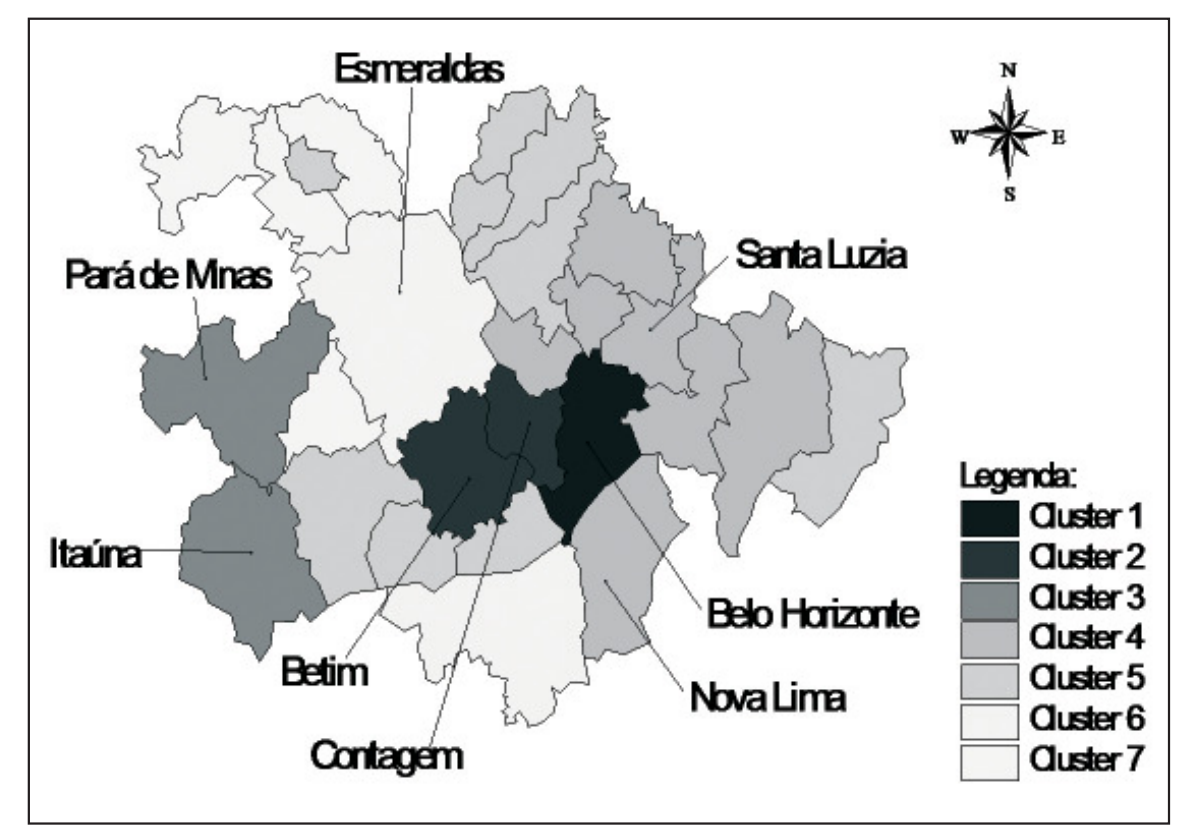

Figura 3 - Região de Belo Horizonte e Entorno Metropolitano

Fonte: Elaborada pelos autores com base na malha municipal digital de 2002 (IBGE).

Devido à sua dinâmica complementar de conurbação, Belo Horizonte será aqui analisada em conjunto com seu entorno metropolitano. A Região Metropolitana de Belo Horizonte é a terceira maior aglomeração urbana do país e a hipercentralidade da capital e sua primazia urbana são evidenciadas pelas pequenas cidades que caracterizam seu entorno, com poucas de maior escala e densidade urbanas (SIMÕES; HERMETO; AMARAL, 2005). Tamanha sua dissimilaridade em relação a 
seu entorno, a capital encontra-se como indivíduo único de sua região homogênea - Figura 1 - e apresentou em 2000 o maior nível de desenvolvimento do Estado, enquanto RMBH atingiu apenas a sétima colocação.

O entorno metropolitano aqui apresentado possui poucas diferenças da Região Metropolitana de Belo Horizonte definida pela Lei Complementar $n^{\circ}$ 63, de 10 de janeiro de 2002, dentre as quais se destacam a inserção de Itaúna e Pará de Minas, que se encontram no chamado Colar Metropolitano. Apesar da forte polarização e centralidade exercida por Belo Horizonte em Minas Gerais, a zona de influência da capital restringe-se à porção central e norte do Estado, ficando o restante sob influência de São Paulo, Rio de Janeiro e Brasília (INSTITUTO BRASILEIRO DE GEOGRAFIA E ESTATÍSTICA, 2000).

A região concentra mais de $33 \%$ da população e quase $54 \%$ de todo o valor da transformação industrial (VTI) do Estado. Cabe ressaltar a presença do complexo metal-mecânico, que, em conjunto com a indústria mínero-metalúrgica do Vale do Aço, colocam Minas Gerais como principal polo mínero-metal-mecânico do país. A taxa de urbanização do entorno metropolitano atinge o nível de $95 \%$ da população, enquanto toda a população da capital habita áreas urbanas. A média de anos de estudo da população de 25 anos ou mais é também um diferencial da região e atinge 8,05 anos em Belo Horizonte, enquanto a média estadual é de 5,6 anos de estudo. Além disso, o percentual de crianças fora da escola se manteve desde os anos 70 abaixo da média estadual, atingindo 2,6\% em 2000 enquanto no restante do Estado 4,5\% das crianças estavam fora da escola.

O parque industrial da região é considerado um dos mais importantes do país e se concentra principalmente na montagem de veículos automotores, metalurgia básica e em atividades de refino de petróleo Refinaria Gabriel Passos. O cinturão industrial de Belo Horizonte constitui o polo estruturante do processo de industrialização de Minas Gerais, no qual Contagem, maior polo industrial do Estado, e agora Betim desempenham os papéis de grandes cidades industriais. Destacam-se ainda setores emergentes de alta tecnologia, como o setor de informática, em particular o de software, o setor de biotecnologia, considerado o mais importante da América Latina (INSTITUTO DE PESQUISA ECONÔMICA APLICADA, 2001), fármacos e química fina, além do setor de controle de automação industrial, apoiados por importantes instituições públicas de pesquisa.

O Cluster 1, apresentado na Figura 3, é composto apenas por Belo Horizonte, que também compõe sozinha sua região homogênea. A capital de Minas Gerais é e foi fundada em 1897 para ser o grande lócus político-administrativo do Estado, e possui 74,7\% de seus ocupados em 
atividades do setor terciário. A concentração da oferta de serviços na capital, tanto tradicionais como modernos, é de intensidade tal que o gap de diversificação terciária entre Belo Horizonte e seu entorno metropolitano repercute negativamente na capacidade de sua inserção na hierarquia urbana metropolitana brasileira (SIMÕES; HERMETO; AMARAL, 2005). Tal concentração e polarização são ainda refletidas internamente em Belo Horizonte, onde as unidades de planejamento Centro e Savassi respondiam em 2003 por nada menos que 38,6\% da arrecadação municipal de ISSQN, somando um montante de arrecadação 2,3 vezes maior que o de Uberlândia, que é o segundo município do Estado em arrecadação de ISSQN.

O Cluster 2, composto pelos municípios de Betim e Contagem, caracteriza-se principalmente pela alta concentração populacional (somam quase $5 \%$ da população do Estado), elevado grau de urbanização (98,5\%) e grande peso da indústria na estrutura produtiva (20\% do emprego). Já o Cluster 3, composto por Itaúna e Pará de Minas, caracteriza-se pelos elevados índices de urbanização (93\%), atendimento sanitário (94,6\%) e rendimento médio $(\mathrm{R} \$ 550,92)$. A estrutura produtiva destes municípios destaca-se pela convivência entre atividades agropecuárias, serviços de complexidade intermediária e razoável produção industrial, concentrada principalmente nas atividades de tecelagem, metalurgia básica, fabricação de produtos de metal e peças para veículos automotores, complementares ao polo metal-mecânico. O Cluster 4 caracteriza-se por alguma produção industrial e grande peso do setor terciário, que em Sabará reponde por mais de $77 \%$ do emprego do município. São municípios eminentemente dependentes do lugar central metropolitano, considerados como cidades-dormitório, cujo setor terciário concentra-se em serviços pessoais menos complexos, de centralidade local (SIMÕES; HERMETO; AMARAL, 2005). Os demais clusters caracterizam-se ordenadamente pela perda de importância da indústria na estrutura produtiva, redução no nível de urbanização, população, anos de estudo e renda média.

\subsubsection{Regiões de Juiz de Fora, Centro-Leste, Centro e Sudeste}

Para facilitar a compreensão e análise, toda a porção sudeste de Minas Gerais será apresentada conjuntamente nesta seção. A região de Juiz de Fora, composta por apenas cinco municípios - Juiz de Fora, Barbacena, Santos Dumont, Ewbank da Câmara e São João del Rei atingiu em 2000 a segunda colocação em nível de desenvolvimento. Conforme explicitado na Seção 4.2, tal colocação foi favorecida pela pequena quantidade de municípios na região, que possibilitou ao conjunto auferir uma média ainda mais elevada nas variáveis utilizadas 
para o cálculo do nível de desenvolvimento. A baixa coesão territorial da Zona da Mata explica sua fragmentação em termos de fortes disparidades de desenvolvimento relativa entre as regiões homogêneas por nós identificadas.

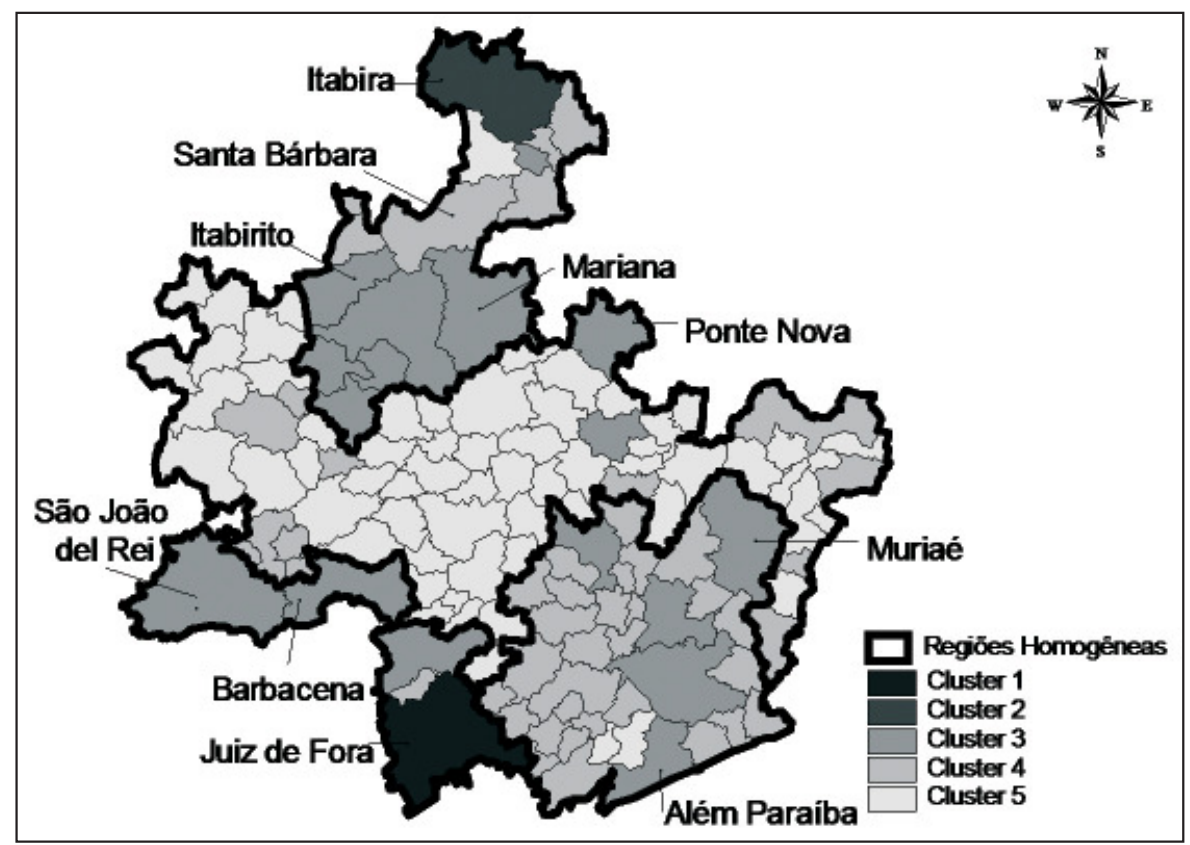

Figura 4 - Regiões de Juiz de Fora, Centro-Leste, Centro e Sudeste Fonte: Elaborada pelos autores com base na malha municipal digital de 2002 (IBGE).

A região encontra-se sob influência principal do Rio de Janeiro, sendo Juiz de Fora o grande centro polarizador regional, cuja centralidade é classificada como "muito forte" (INSTITUTO BRASILEIRO DE GEOGRAFIA E ESTATÍSTICA, 2000). Destaca-se pelo elevado grau de urbanização, uma vez que $96,3 \%$ de sua população habita áreas urbanas, enquanto nas demais regiões Centro-Leste, Centro e Sudeste são 78,5\%. A renda familiar per capita na região em 2000 foi 32,2\%, maior que a média do Estado. A escolaridade média da população - 6,93 anos de estudo - é menor apenas que de Belo Horizonte e atinge 1,34 anos de estudo a mais que a média mineira. A taxa de analfabetismo é de apenas $5,6 \%$, menos da metade da média estadual, e o percentual de crianças que trabalham é de 2,8\%, enquanto no Estado são 6,7\%.

Já a região Centro, composta por quinze municípios, atingiu em 2000 a $5^{\text {a }}$ colocação em nível de desenvolvimento relativo no Estado e está sob influência principal de Belo Horizonte (INSTITUTO BRASILEIRO DE GEOGRAFIA E ESTATÍSTICA, 2000). Apesar de ter uma renda média abaixo da média estadual - $\mathrm{R} \$ 292,13$, enquanto em Minas Gerais a média é de $R \$ 335,89$-, a região encontra-se ligeiramente acima da 
média estadual em praticamente todas as demais variáveis analisadas. Cabe ressaltar que 90,6\% da população habita áreas urbanas, 81,8\% possui escoamento por rede geral, 39\% possui automóvel e a escolaridade média é de 5,92 anos de estudo, enquanto no Estado esses valores são de $81,7 \%$ de população urbana, $68,2 \%$ de escoamento por rede geral, 33\% com automóvel e a média de anos de estudo é de 5,6.

Ocupando em 2000 a $9^{a}$ colocação em nível de desenvolvimento no Estado está a região Sudeste. Composta por 36 municípios, a região encontra-se sob influência principal de Juiz de Fora. O indicador regional que mais diverge da média mineira é o tamanho das famílias do Sudeste. Apenas 18,6\% das famílias possuem cinco membros ou mais, enquanto no Estado são 22,9\%. O abastecimento de água é feito por rede geral para $85,1 \%$ da população, a taxa de urbanização é de $85,7 \%$ e a escolaridade média atinge 5,35 anos de estudo. Os demais indicadores regionais encontram-se bem próximos da média estadual.

A região Centro-Leste, composta por 73 municípios, atingiu em 2000 a $11^{\mathrm{a}}$ colocação em nível de desenvolvimento em Minas Gerais e chama a atenção pelo desenvolvimento bastante inferior em relação às regiões vizinhas. É caracterizada por municípios de pequeno porte, com média de população inferior a 9 mil habitantes e taxa de urbanização de $61 \%$. A renda média na região é a quarta menor do Estado - $\mathrm{R} \$ 219,10 \mathrm{em}$ 2000 - e, devido à pouca densidade populacional, o rendimento total médio dos municípios dessa região é o segundo menor de Minas Gerais. Apenas $61,3 \%$ da população possui abastecimento de água por rede geral, e 52,8\% tem acesso a escoamento por rede geral, o que coloca a região dentre as três de pior infraestrutura sanitária em Minas Gerais.

As quatro regiões, analisadas conjuntamente, possuem $16,9 \%$ de sua mão de obra empregada em atividades agropecuárias ou extrativas, que vêm perdendo importância no Estado e caracterizam-se pela não modernização e baixa produtividade (INSTITUTO DE PESQUISA ECONÔMICA APLICADA, 2001). A região é responsável por 10,3\% da produção de leite, 6,7\% do rebanho bovino e 4,6\% da produção agrícola de Minas Gerais. Leopoldina, São João del Rei e Muriaé respondem por 13,7\% da produção regional de leite, Leopoldina e Muriaé são responsáveis também por 10\% do rebanho bovino e Carandaí, Lagoa Dourada, Carangola e Entre Rios de Minas respondem por 17,5\% da produção agrícola regional, que concentra-se principalmente no cultivo de café, cana, tomate, banana e arroz. Cabe ainda ressaltar que a microrregião de Ponte Nova detém o maior rebanho suíno do Estado, concentrando 12\% do total do Estado (BANCO DE DESENVOLVIMENTO DE MINAS GERAIS, 2002).

O valor da transformação industrial na região corresponde a $21,1 \%$ do total de Minas Gerais, sendo Itabira e Juiz de Fora responsáveis por 
49,3\% desse valor. Os principais setores regionais são: extração de minério de ferro - principalmente Cia. Vale do Rio Doce, em Itabira -, produção de laminados não-planos de aço - Cia. Siderúrgica Belgo Mineira, em João Monlevade -, produção de ferro, aço e ferro-ligas - Açominas S/A, em Ouro Branco, - e fabricação de automóveis, camionetas e utilitários - Daimler Chrysler do Brasil, em Juiz de Fora. Estes quatro setores respondem por 75\% do valor da transformação industrial na região.

Juiz de Fora compõe sozinha o Cluster 1 regional. Considerada uma das mais importantes cidades de Minas Gerais, conta com bons sistemas rodoviário e ferroviário e um aeroporto com voos regulares. Com equipamentos urbanos de qualidade, a cidade possui centros de formação importantes para oferta de mão de obra qualificada que, juntamente com o distrito industrial e os terrenos a baixo custo, tornam o município um polo de grande potencial de crescimento, ainda mais quando consideramos sua posição geográfica privilegiada (INSTITUTO DE PESQUISA ECONÔMICA APLICADA, 2001). Juiz de Fora é responsável por 5,7\% de toda a arrecadação de ISSQN do Estado, o que corresponde a $44,7 \%$ da arrecadação regional. O município, que possui $77 \%$ de sua mão de obra no setor terciário, contava com 47 agências bancárias em 2004, número inferior apenas a Belo Horizonte e Uberlândia. Cabe ainda ressaltar a presença da Universidade Federal de Juiz de Fora, que oferece 33 cursos de graduação, 15 Mestrados e dois Doutorados, além de cursos de educação profissional, média e fundamental. Mas, paradoxalmente, sua evolução nos últimos 50 anos tem revelado ter sido incapaz de manter a coesão territorial da Zona da Mata.

Também como integrante única de seu grupo está a cidade de Itabira. Apesar de possuir um sistema de transporte rodoviário de má qualidade, o município dispõe de um sistema ferroviário de importância-chave para o escoamento de sua produção. Conta ainda com dois distritos industriais, mas ainda incapazes de realizar sua conversão produtiva industrial com a desativação das atividades da Cia. Vale do Rio Doce. Destacam-se sua boa infraestrutura urbana, como aterro sanitário, coleta seletiva de lixo, Programa Saúde da Família e a construção de uma central de tratamento de esgoto. Apesar de ter perdido dinamismo nos últimos anos (INSTITUTO DE PESQUISA ECONÔMICA APLICADA, 2001), Itabira de fato não é mais $90 \%$ de ferro nas calçadas, nem apenas uma fotografia na parede.

O Cluster 3 é composto por 17 municípios, com média de população e taxa de urbanização superiores a 60 mil habitantes e 91\%, respectivamente. Além disso, são municípios com boa infraestrutura e equipamentos urbanos de qualidade, possuindo em média 6,12 agências bancárias e 89\% de escoamento sanitário feito por rede geral. O emprego 
concentra-se nos setores terciário - 71\% - e secundário - 15\%. Apesar do peso do setor de serviços na economia destes municípios, eles são considerados eminentemente industriais, uma vez que são responsáveis por nada menos que $9 \%$ de todo o VTI estadual.

O Cluster 4 é composto por municípios menores, com média de 10 mil habitantes. A taxa de urbanização desses municípios é de $80 \%$, e o setor agropecuário assume importância bem maior, sendo responsável por $20 \%$ do emprego no cluster e 19\% da produção regional. Já o Cluster 5 , composto principalmente pela região Centro-Leste, caracteriza-se por seu baixo desenvolvimento e é uma das áreas mais pobres do Estado. Apenas $47 \%$ da população habita áreas urbanas, a escolaridade e renda médias são de 3,7 anos de estudo e $\mathrm{R} \$ 284,16$, e 48\% do emprego é do setor agropecuário, de baixa modernização e/ou subsistência.

\subsubsection{Região de Diamantina}

A região de Diamantina, composta por 63 municípios, apresentouse em 2000 com o pior nível de desenvolvimento relativo no Estado. Tal fato toma proporções ainda maiores quando consideramos a proximidade desta região da capital Belo Horizonte, como mostra a Seção 4.2. A região responde por $1,8 \%$ da produção agrícola, 3,7\% da produção de leite, $4,2 \%$ do rebanho bovino e 3\% do VTI estadual. As taxas de urbanização e de escoamento por rede geral são de $55 \%$, a escolaridade e renda médias são de 4,38 anos de estudo e $R \$ 306,14$. Além disso, o acesso a muitos municípios não é asfaltado e grande parte da população em idade produtiva migra para demais regiões em busca de oportunidade de emprego. 


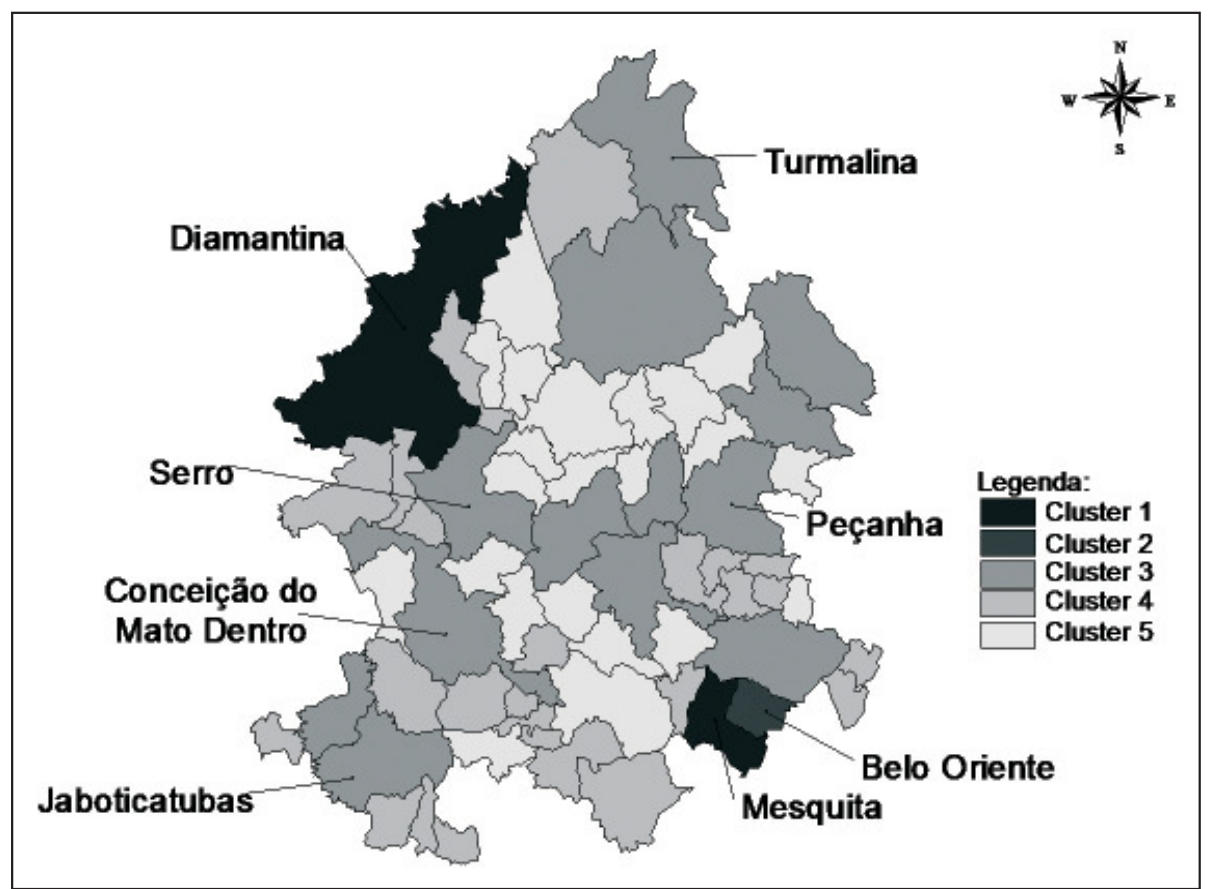

Figura 5 - Região de Diamantina

Fonte: Elaborada pelos autores com base na malha municipal digital de 2002 (IBGE).

Destaca-se a indústria de celulose CENIBRA S/A em Belo Oriente, responsável por 91,2\% do VTI regional. Diamantina e Mesquita exercem a pouca centralidade urbana existente na região. Apesar do programa de linha de crédito especial do Banco de Desenvolvimento de Minas Gerais (BDMG) para municípios próximos à Estrada Real, como é o caso de grande parte da região, o turismo local é ainda pouco desenvolvido, uma vez que a qualificação da população não é suficiente para seu desenvolvimento.

\subsubsection{Norte de Minas}

A região Norte atingiu, em 2000 , a $13^{\mathrm{a}}$ colocação em nível de desenvolvimento relativo às demais regiões de Minas Gerais. As principais características destes municípios são os baixos níveis de renda média, total de rendimentos e escolaridade. Conforme apresentado na Seção 4.2, a renda média na região vem se distanciando de seu nível em Minas Gerais durante todo o período analisado e a escolaridade da população, apesar de se aproximar da média estadual, ainda é bastante inferior. Além disso, a diferença no crescimento populacional e no percentual de pessoas com 25 anos ou mais entre a região e o Estado tem se intensificado nas últimas quatro décadas. Em 1970, 19,7\% da população mineira encontrava-se na região Norte. Destes, 32,7\% tinham 25 anos ou mais, enquanto no Estado eram 36,2\%. Já em 2000, apenas 15,8\% da popu- 
lação de Minas Gerais habitava a região Norte, e a diferença entre o percentual de adultos passou de 3,5 pontos percentuais para 6,4 p.p.

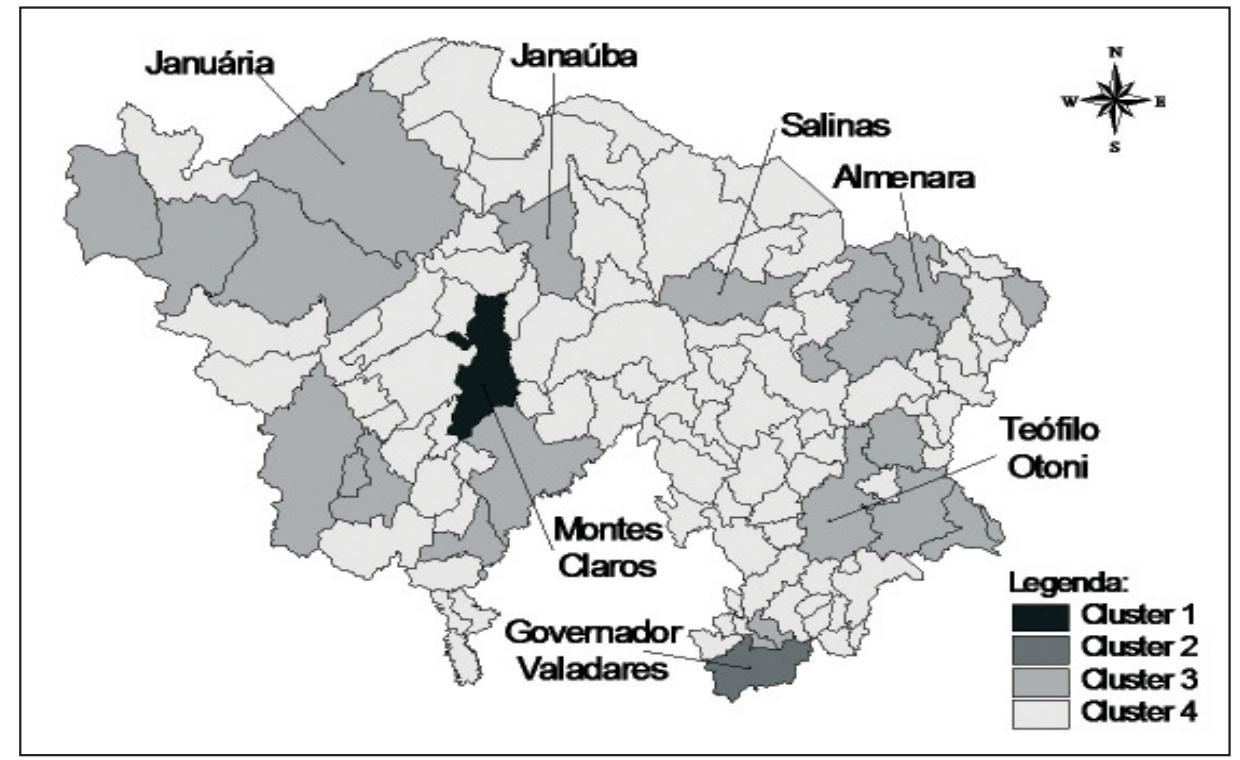

Figura 6 - Região Norte

Fonte: Elaborada pelos autores com base na malha municipal digital de 2002 (IBGE).

Considerando que as famílias nortistas possuem em média $25 \%$ a mais de filhos que o restante do Estado, uma das explicações para os menores crescimento e envelhecimento populacional na região, além de menor expectativa de vida, seria a migração seletiva para regiões de maior desenvolvimento, conforme as teorias de desenvolvimento apresentadas na Seção 1. Ou seja, a polarização, ou os efeitos regressivos, das regiões desenvolvidas de Minas Gerais sobre a região Norte resultaria na migração da população em idade produtiva em busca de melhores oportunidades de trabalho e renda.

O emprego regional concentra-se principalmente em atividades agropecuárias ou extrativas, que respondem por 36,2\% da mão de obra. Todavia, a atividade tem pouco dinamismo, em geral não possui objetivos comerciais e é pouco capitalizada. A região responde por $10 \%$ da produção agrícola e $24 \%$ do rebanho bovino de Minas Gerais. A agricultura tem caráter de subsistência e a pecuária é em grande parte extensiva. Destacam-se apenas o rebanho bovino de Carlos Chagas e de São Francisco, a produção de ovos de galinha na região de Montes Claros e de frutas na região de Janaúba.

A atividade industrial, apesar dos benefícios oferecidos por grande parte da região que se encontra na área da SUDENE, é praticamente inexpressiva em Minas Gerais, sendo responsável por apenas 3\% do valor da transformação industrial do Estado. Destaca-se, no entanto, a importância industrial do município de Montes Claros. Se somarmos a 
ele Pirapora e Governador Valadares, os três municípios concentram $73 \%$ do VTI regional. Os principais setores são: fabricação de artigos de tecido de uso doméstico - principalmente COTEMINAS, em Montes Claros -, produção de ferro, aço e ferro-ligas - Minas Ligas, em Pirapora, - e tecelagem de algodão - Cia. de Fiação e Tecidos Sto. Antônio, também em Pirapora -, que respondem por 35\% do VTI da região.

Compondo sozinhos o Cluster 1 e o Cluster 2 respectivamente, Montes Claros e Governador Valadares são considerados enclaves de renda concentrada com poucas possibilidades de integração produtiva regional e concentram 56\% do VTI e 51\% da arrecadação de ISSQN regional.

Montes Claros destaca-se pelo seu grande parque industrial e equipamentos urbanos únicos em sua região. Encontram-se no município oito hospitais, uma universidade estadual e um aeroporto com voos regionais regulares, além de entroncamentos rodoviários e ferroviários. O município possui taxa de urbanização de 94\% e 93\% da população de 307 mil habitantes e é atendida com escoamento sanitário por rede geral. Já Governador Valadares, tem uma taxa de urbanização de 96\%, possui 19 agências bancárias e $75 \%$ de sua mão de obra concentra-se no setor terciário. Os 217 mil habitantes da cidade contam com sete hospitais, com a Universidade do Vale do Rio Doce (UNIVALE), um aeroporto com voos regionais regulares e boa infraestrutura de transportes ferroviário e rodoviário, além do pico do Ibituruna, que transformou a cidade na capital mundial do voo livre.

O Cluster 3 é composto por 23 municípios com, em média, 38 mil habitantes. São municípios urbanos, mas a agropecuária de subsistência é atividade primordial para boa parte da população. Apresentam atividade industrial de pouca relevância, com exceção de Pirapora, Várzea da Palma e Bocaiúva. Os municípios possuem em média 2,91 agências bancárias e $63,6 \%$ de taxa de escoamento sanitário por rede geral.

A infraestrutura e qualidade de vida nos municípios do Cluster 4 são ainda piores. São 88 municípios dentre os mais pobres do Estado, com, em média, 16 mil habitantes. É no emprego agropecuário que $50 \%$ da população busca a renda média de $\mathrm{R} \$ 259,41$. A escolaridade média é de apenas 3,8 anos de estudo e somente $50 \%$ da população possui escoamento sanitário por rede geral.

\section{Considerações Finais}

De acordo com a sugestão dos dados inter e intrarregionais, a disparidade no processo de desenvolvimento em Minas Gerais atinge proporções tão grandes que a regionalização contribuiu menos para o 
agrupamento de municípios com processos semelhantes e mais para a segmentação daqueles onde o desenvolvimento se deu de forma mais desigual. Ou seja, os nossos resultados confirmam que ao longo dos últimos trinta anos da economia mineira, período marcado por fortes mudanças estruturais de sua base produtiva, manteve-se a característica histórica da extrema desigualdade de seu desenvolvimento.

Conforme sugerem as teorias de desenvolvimento, para uma política de desenvolvimento regional, o investimento de capital deve ser de tal ordem que gere encadeamentos e interdependências entre os setores e os agentes produtivos, capazes de transbordar seus efeitos para além dos estreitos limites de seu centro original de irradiação e crescentemente incorporar regiões mais atrasadas e periféricas. Não há, portanto, desenvolvimento regional sem integração econômica e coesão territorial.

Um importante consenso entre os autores clássicos das teorias estruturalistas de desenvolvimento dos anos cinquenta, como RosensteinRodan, Nurkse, Myrdal e Hirschman, é o papel crucial do Estado na coordenação dos agentes para realização dos investimentos em capital social básico (infraestrutura) e atividades produtivas diretas. O planejamento público possibilita coordenar as decisões de investimento dos agentes públicos e privados para que o provimento das modalidades de capital fixo ocorra numa sequência tal que explore sinergias e reduza as incertezas empresariais. Segundo Hirschman (1958), essas incertezas afetam a capacidade de investir dos empresários domésticos das regiões menos desenvolvidas e o instrumento do investimento induzido, via planejamento estatal, torna-se ingrediente necessário para uma estratégia bem sucedida de desenvolvimento econômico.

O caso do investimento público em Minas Gerais no período analisado é sua crescente redução a partir dos anos oitenta e a ausência de planejamento econômico na sua realização, acontecendo cada vez mais de modo disperso e desconexo. Como enfatizado por aqueles autores clássicos, a questão do investimento em regiões atrasadas é antes de tudo um problema de planejamento e formulação de projetos bem definidos, que de recursos financeiros propriamente ditos, já que estes são escassos por definição, tratando-se de economias estruturalmente com baixo nível de acumulação de capital. Além disso, o planejamento do crescimento econômico do Estado deve se atentar também às questões sociais e não negligenciá-las, como diagnosticou Diniz (1981), quando do grande crescimento da década de 70.

A caracterização regional apresentada neste trabalho abre então um largo campo de necessária investigação sobre as causas do atraso e estagnação de determinadas regiões. A compreensão deste processo, 
por sua vez, pode auxiliar na busca e formulação de planos e estratégias bem delineadas, que possam lograr êxito na redução das disparidades e no desenvolvimento econômico e social do Estado de Minas Gerais como um todo.

Nossa contribuição específica foi resgatar a questão do desenvolvimento numa perspectiva multidimensional e a partir daí definir uma regionalização que contemple simultaneamente indicadores econômicos, sociais e demográficos. A regionalização obtida representa um mapeamento tanto da coesão territorial do desenvolvimento das regiões mineiras, bem como de sua fragmentação, o que efetivamente pode servir para a intervenção do planejamento público em áreas-problema da economia estadual. Cabe lembrar que a regionalização apresentada neste trabalho parte do escopo restrito das dimensões de desenvolvimento consideradas, cuja vantagem são resultados mais precisos para o objetivo deste trabalho, mas que geram grandes distorções caso sejam outros os objetivos para os quais a regionalização possa ser utilizada. $\mathrm{O}$ fato de não considerarmos aqui dimensões físicas, políticas, históricas e culturais, entre outros fatores, deve estar sempre em vista. A nosso ver, a partição territorial das Regiões de Planejamento ainda preserva em seus critérios a ênfase na homogeneidade físico geográfica, enquanto a partição do presente trabalho enfatiza a homogeneidade socioeconômica, sem deixar de preservar um escopo da heterogeneidade intrarregional. É interessante observar que nas Regiões de Planejamento onde foi possível uma integração regional no seu processo de desenvolvimento, via complementaridades e integração de sua base produtiva, os resultados obtidos de nossa regionalização foram quase coincidentes com os da partição oficial. São lugares onde o desenvolvimento econômico espalhou-se no todo regional, possibilitando sua coesão territorial. Este é o caso típico do Triângulo Mineiro. Na direção oposta, estão os casos da Região Central e da Zona da Mata. Belo Horizonte, mesmo sendo a capital estadual, não foi capaz de ampliar seu processo de integração produtiva além de um limitado raio de influência geográfica, o chamado segundo colar metropolitano, e mesmo assim com muitos buracos internos de áreas de pobreza e vazio econômico. O resultado foi a fragmentação da Região Central, que combina áreas de forte desenvolvimento, localizado em seu centro radial, e áreas desarticuladas, como as do lado setentrional da capital, em direção ao Jequitinhonha e Norte de Minas. Por sua vez, Juiz de Fora perdeu centralidade urbana com a decadência secular de sua indústria têxtil, sendo incapaz de comandar a reconversão produtiva da Zona da Mata após o ciclo cafeeiro. O resultado foi a pobreza e a regressão econômica de boa parte de sua antiga área de influência geográfica. 
A regionalização obtida reflete, assim, uma importante faceta da dinâmica desigual do desenvolvimento recente da economia mineira, que combina coesão territorial de sua parte mais virtuosa e fragmentação territorial de sua parte mais desarticulada, efetivamente excluída dos frutos do progresso econômico brasileiro dos últimos trinta anos.

\section{Referências}

ABLAS, L. A. A teoria do lugar central: bases teóricas e evidências empíricas: estudo do caso de São Paulo. 1978. 199f. Tese (Doutorado em Geografia) - Universidade de São Paulo, São Paulo, 1978.

ASSUNÇÃO, R.; LAGE, J.; REIS, E. Análise de conglomerados espaciais via árvore geradora mínima. Revista Brasileira de Estatística. Rio de Janeiro, v. 63, n. 220, p. 7-24, 2002.

BANCO DE DESENVOLVIMENTO DE MINAS GERAIS. Minas Gerais do século XXI. v. 2, Belo Horizonte: Rona, 2002.

BOUDEVILLE, J. Los espacios económicos. Buenos Aires: Editorial Universitaria de Buenos Aires, 1965.

CHEIN, F.; LEMOS, M.; ASSUNÇÃO, J. Desenvolvimento desigual: evidências para o Brasil. In: ENCONTRO NACIONAL DE ECONOMIA, v. 33, 2005, Natal. Anais... Natal: ANPEC, 2005.

CHRISTALLER, W. Central places in southern Germany. New Jersey: Englewood Cliffs, 1966.

CUNHA, A.; SIMÕES, R.; PAULA, J. Regionalização e história: uma contribuição introdutória ao debate teórico-metodológico. Belo Horizonte: UFMG/Cedeplar, 2005. 24p. [Texto para Discussão, 260].

DINIZ, C. Desenvolvimento poligonal no Brasil: nem desconcentração nem contínua polarização. Belo Horizonte: Nova Economia, Belo Horizonte, v. 3, n. 1, p.35-64, 1993.

. Estado e capital estrangeiro na industrialização mineira. Belo Horizonte: Imprensa da UFMG, 1981. 260p.

DINIZ, C.; CROCCO, M. A. Reestruturação econômica e impacto regional: o novo mapa da indústria brasileira. Nova Economia, Belo Horizonte, v. 6, n. 1, p. 77-103, 1996.

FUJITA, M.; KRUGMAN, P.; VENABLES, A. The spatial economy: cities, regions, and international trade. Cambridge: MIT Press, 1999.

FUJITA, M.; THISSE, J-F. Economics of agglomeration. Cambridge: University Press, 2002.

HIRSCHAMN, A. O. The strategy of economic development. New Haven: Yale University, 1958.

INSTITUTO BRASILEIRO DE GEOGRAFIA E ESTATÍSTICA. Regiões de influência das cidades 1993. Rio de Janeiro: IBGE, 2000.

INSTITUTO DE PESQUISA ECONÔMICA APLICADA. Caracterização e tendências da rede urbana do Brasil: redes urbanas regionais: Sudeste. Brasilia: IPEA, v. 5, 168p., 2001.

JACOBS, J. The economy of cities. New York: Random House, 1969. 
KAUFMAN, L.; ROUSSEEUW, P. Finding groups in data: an introduction to cluster analysis. New York: John Wiley, 1990.

LEMOS, M. B. Espaço e capital: um estudo sobre a dinâmica centro-periferia. v. 2, 1988. Tese (Doutorado em Economia) - Programa de Pós-Graduação em Ciências Econômicas, Instituto de Economia, Universidade Estadual de Campinas, Campinas, 1988.

LEMOS, M. B. et al. A dinâmica urbana das regiões metropolitanas brasileiras. In: ENCONTRO NACIONAL DE ECONOMIA, v. 29, 2001, Salvador, BA. Anais... Salvador: ANPEC, 2001 [1 CD-ROM].

LÖSCH, A. The economics of location. London: Yale University, 1967.

MANLY, B. F. J. Multivariate statistical methods: a primer. London: Chapman and Hall, 1986.

MARSHALL, A. Princípios de economia: tratado introdutório. 2. ed. São Paulo: Nova Cultural, 1985. 2 v. [Série Os economistas].

MYRDAL, G. Economic theory and under-developed regions. London: Gerald Duckworth, 1957.

RAY, D. Development economics. Princeton: Princeton University, 1998.

SIMÕES, R.; HERMETO, A.; AMARAL, P. Rede urbana metropolitana: uma análise da estrutura terciária de Belo Horizonte. In: ENCONTRO REGIONAL DE ECONOMIA NORDESTE, v. 10, 2005. Fortaleza, CE. Anais... Fortaleza: ANPEC, 2005 [1 CD-ROM]. 
Apêndice

\begin{tabular}{|c|c|c|c|c|c|c|c|c|c|c|c|}
\hline 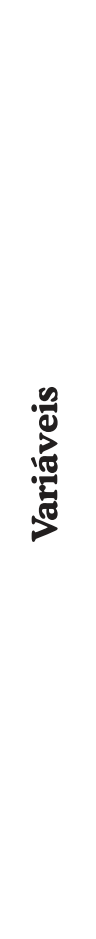 & 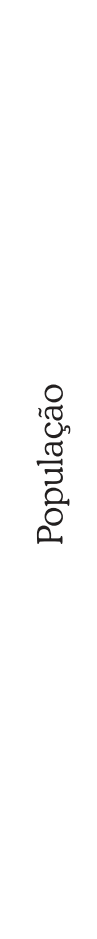 & 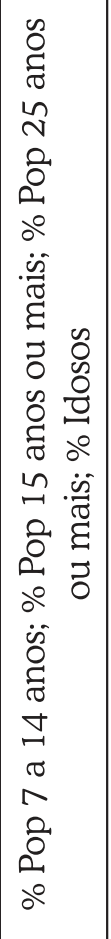 & 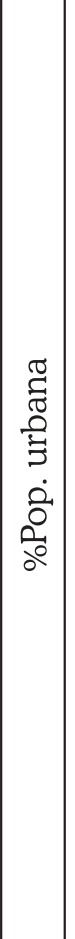 & 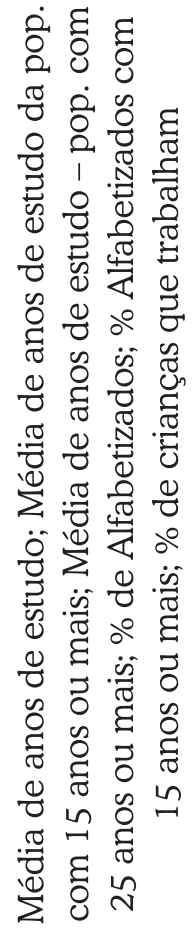 & 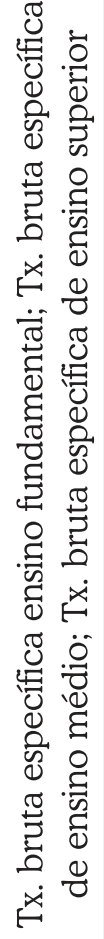 & 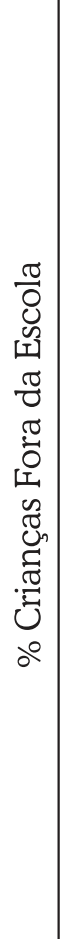 & 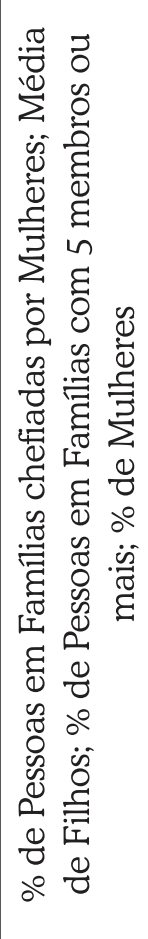 & 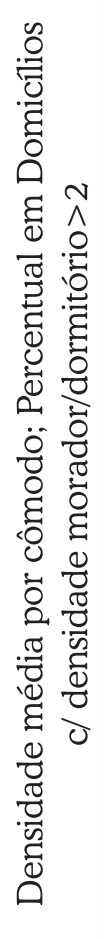 & 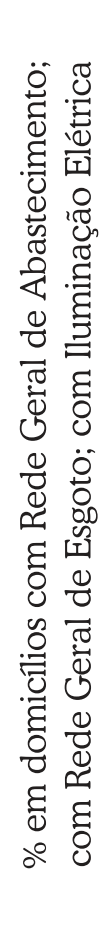 & 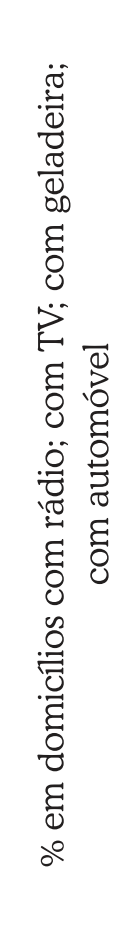 & 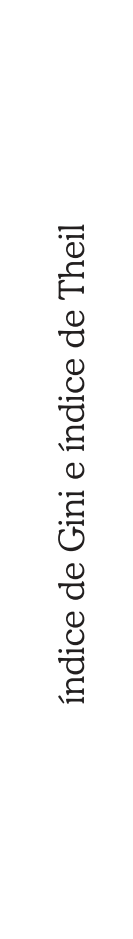 \\
\hline 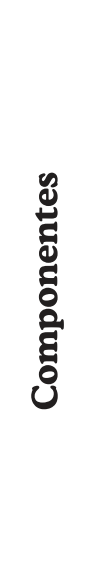 & 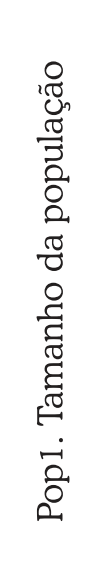 & 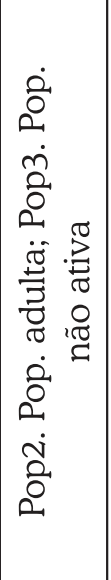 & 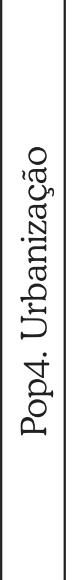 & 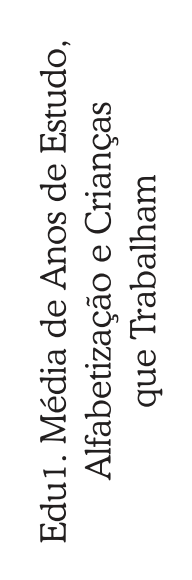 & 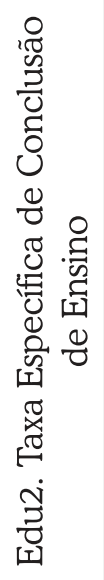 & 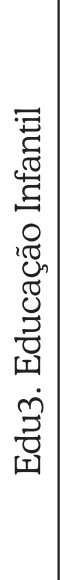 & 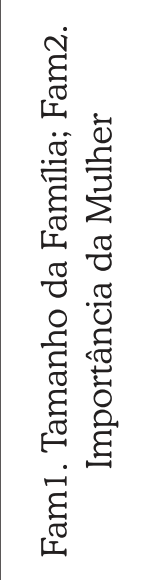 & 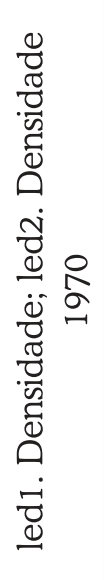 & 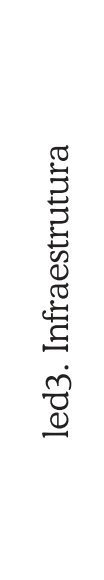 & 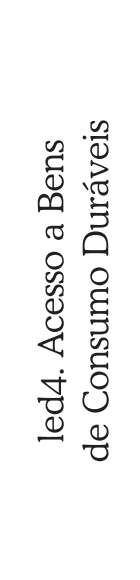 & 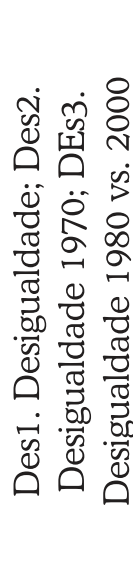 \\
\hline 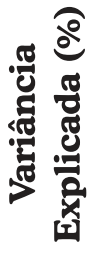 & $\begin{array}{l}\infty \\
\infty \\
\infty \\
\sigma\end{array}$ & $\begin{array}{l}\stackrel{n}{\circ} \\
\stackrel{0}{\circ}\end{array}$ & $\begin{array}{l}\stackrel{\circ}{\curvearrowright} \\
\sigma\end{array}$ & $\begin{array}{l}\infty \\
\dot{\Sigma}\end{array}$ & $\begin{array}{l}\vec{n} \\
\infty \\
\infty\end{array}$ & $\begin{array}{l}\vec{Z} \\
\dot{J}\end{array}$ & $\begin{array}{l}\overrightarrow{7} \\
\stackrel{0}{0}\end{array}$ & $\underset{\infty}{\vec{\sim}}$ & $\stackrel{\sigma}{\sigma}$ & $\begin{array}{l}\stackrel{\infty}{N} \\
\stackrel{\sigma}{\sigma}\end{array}$ & $\begin{array}{l}\stackrel{\circ}{\circ} \\
\stackrel{\infty}{0}\end{array}$ \\
\hline 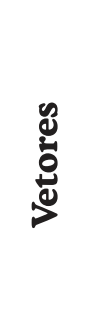 & 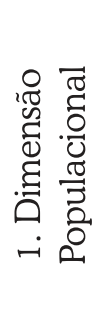 & 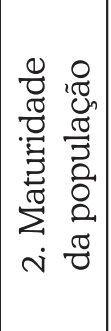 & 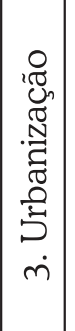 & 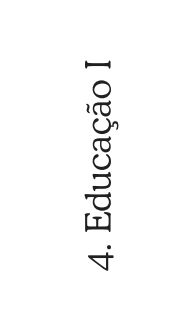 & 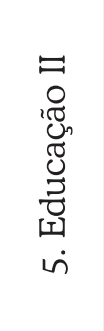 & 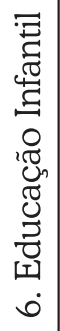 & 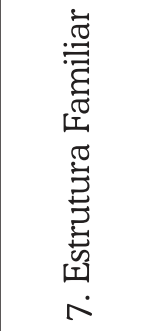 & 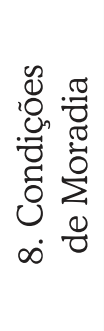 & 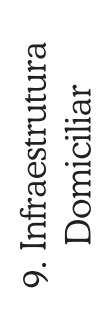 & 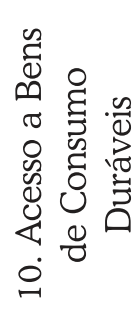 & 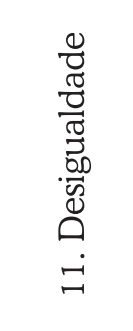 \\
\hline
\end{tabular}




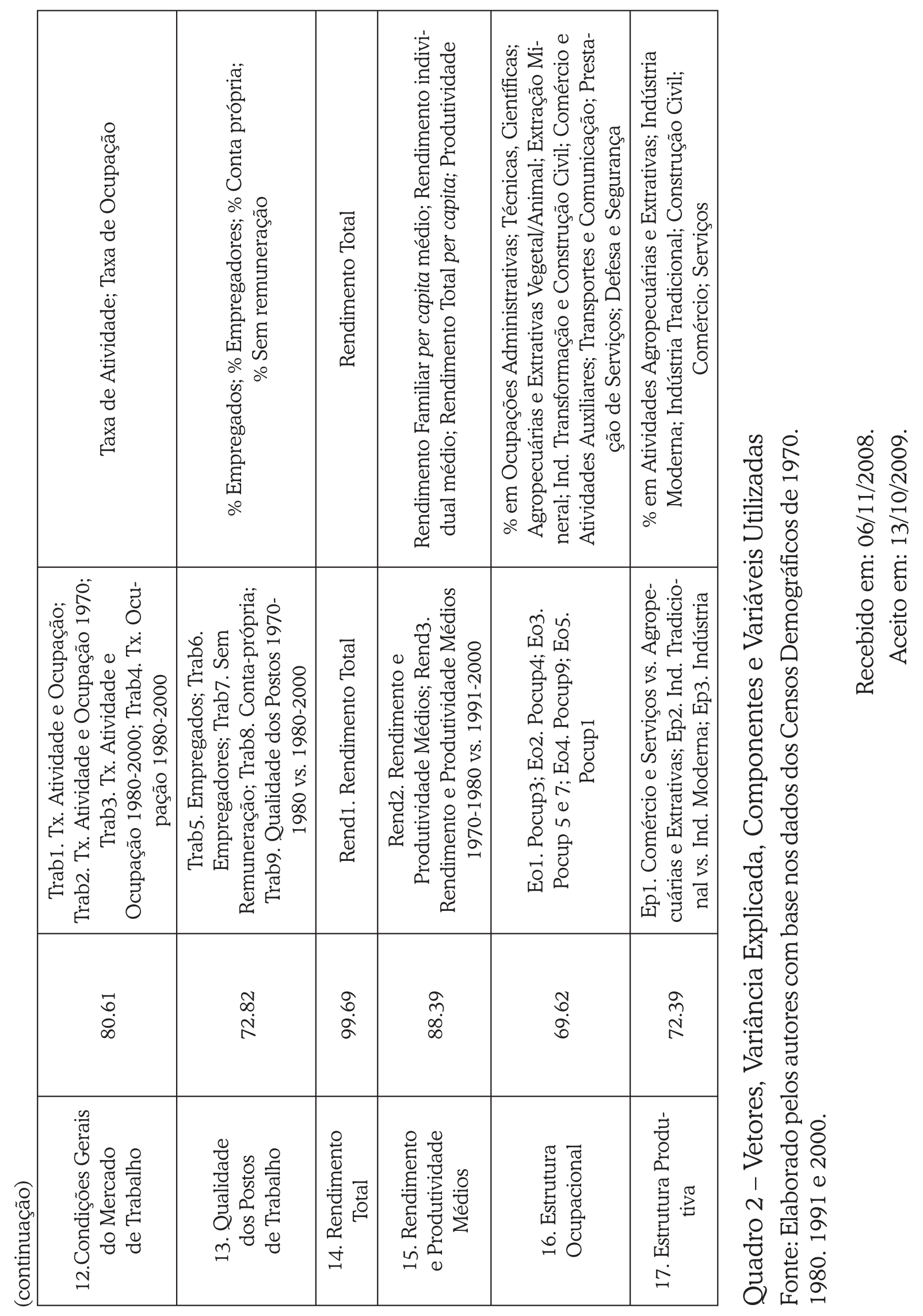

